Annales Geophysicae (2004) 22: 1213-1231

SRef-ID: $1432-0576 / \mathrm{ag} / 2004-22-1213$

(C) European Geosciences Union 2004

\title{
Transpolar arc evolution and associated potential patterns
}

\author{
J. A. Cumnock ${ }^{1,2}$ and L. G. Blomberg ${ }^{2}$ \\ ${ }^{1}$ Center for Space Sciences, University of Texas at Dallas, USA \\ ${ }^{2}$ Alfvén Laboratory, Royal Institute of Technology, Stockholm, Sweden
}

Received: 14 May 2003 - Revised: 14 August 2003 - Accepted: 4 September 2003 - Published: 2 April 2004

\begin{abstract}
We present two event studies encompassing detailed relationships between plasma convection, field-aligned current, auroral emission, and particle precipitation boundaries. We illustrate the influence of the Interplanetary Magnetic Field $B_{y}$ component on theta aurora development by showing two events during which the theta originates on both the dawn and dusk sides of the auroral oval. Both theta then move across the entire polar region and become part of the opposite side of the auroral oval. Electric and magnetic field and precipitating particle data are provided by DMSP, while the Polar UVI instrument provides measurements of auroral emissions. Utilizing satellite data as inputs, the Royal Institute of Technology model provides the high-latitude ionospheric electrostatic potential pattern calculated at different times during the evolution of the theta aurora, resulting from a variety of field-aligned current configurations associated with the changing global aurora.
\end{abstract}

Key words. Ionosphere (auroral ionosphere; electric fields and currents). Magnetospheric physics (magnetosphereionosphere interactions)

\section{Introduction}

High-latitude auroral arcs are often observed on the dawn and dusk sides of the auroral oval during northward Interplanetary Magnetic Field (IMF), of these, rare cases of theta aurora are seen where the transpolar arcs (TPAs) move across the entire polar region. Observations indicate that the TPAs, as part of an expanded dawn or dusk side oval, are located along the poleward boundary of the closed field line region and map to an expanded plasma sheet or plasma sheet boundary layer (Meng, 1981; Frank et al., 1982, 1986; Peterson and Shelley, 1984; Eliasson et al., 1987; Menietti and Burch, 1987; Obara et al., 1988; Hones et al., 1989; Makita et al., 1991). Not all of the TPAs attached to the auroral oval

Correspondence to: J. A. Cumnock

(cumnock@utdallas.edu) move to higher latitudes. The TPAs cross the noon-midnight meridian only when $B_{y}$ changes sign, resulting in a large $B_{z} /\left|B_{y}\right|$ ratio and thus forming a theta aurora when the arc is aligned along the noon-midnight meridian (Cumnock et al., 2002). Theta aurorae are formed, in the Northern Hemisphere, from an expanded dawnside (duskside) emission region when $B_{y}$ changes from negative to positive (positive to negative) (Cumnock et al., 1997). Whereas the motion of the transpolar arc is dependent on the sign of $B_{y}$, brief decreases or southward excursions of IMF $B_{z}$ can enhance the intensity of the transpolar arc and can affect the velocity of its motion.

TPAs are associated with both ion and electron precipitation where the ion precipitation is spread across the arc and electron precipitation is more structured (Frank et al., 1986; Cumnock et al., 2002). The precipitating particle signature associated with theta aurora may also occur as an isolated region (of particles associated with the plasma sheet). The TPA, surrounded by particles normally associated with the polar cap, may map to a bifurcated magnetotail (Frank et al., 1982, 1986; Bythrow et al., 1985; Hoffman et al., 1985).

Ionospheric convection patterns observed during northward IMF generally consist of sunward flow at highest latitudes, in contrast to antisunward flow for southward IMF. A variety of configurations, including spatially dominant onecell patterns and multiple-cell patterns, have been used to explain these observations. The number of cells appears to have a first-order dependence on the ratio of $B_{z}$ to $B_{y}$, resulting in an increasing number of cells and reverse convection at highest latitudes as the IMF becomes more strongly northward (Potemra et al., 1984; Reiff and Burch, 1985; Heelis et al., 1986; Cumnock et al., 1995, and references therein). The convection cells are not necessarily isolated features but may be part of a highly distorted two-cell pattern (Heppner and Maynard, 1987). Observations indicate that TPAs may be associated with either sunward or antisunward flow; as part of a four-cell pattern (Frank et al., 1986; Gusev and Troshichev, 1990; Jankowska et al., 1990; Zanetti et al., 1990), dominant one-cell (Hoffman et al., 1985), three-cell (Carlson et al., 1988; Zanetti et al., 1990; Jankowska et al., 1990), or 

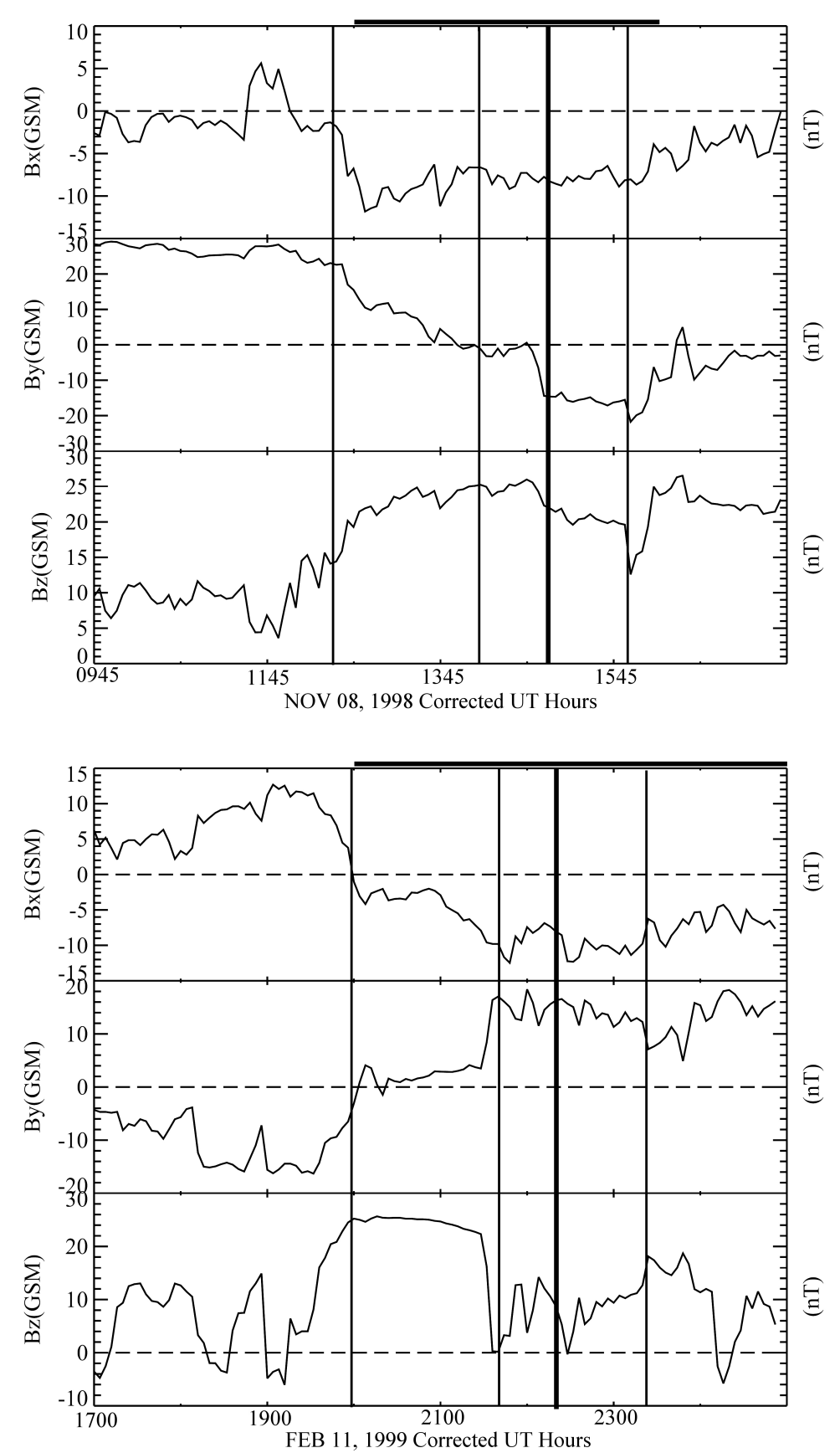

Fig. 1. Shown are magnetic field data from the ACE satellite which orbits the L1 Lagrange point about $200 R_{E}$ sunward of the Earth. IMF GSM components are plotted for our two examples, with 8 November 1998 at the top and 11 February 1999 at the bottom, as a function of corrected universal time (UT plus the estimated propagation time from the satellite to GSM $X=0$ ); in the top panel (8 November 1998) about $45 \mathrm{~min}$ and in the bottom panel (11 February 1999) about $1 \mathrm{~h}$. The thickest vertical line in each plot marks the time when the TPA is aligned along the noon-midnight meridian. The three additional lines mark the time when the DMSP F13 satellite reaches its highest magnetic latitude over the Northern Hemisphere during each orbit. The thick horizontal line at the top of each panel denotes the time period of UVI data shown in Figs. 2 and 3.

distorted two-cell (Robinson and Mende, 1990; Marklund et al., 1991). These studies are based on single observations of TPAs and thus represent different stages of theta aurora evolution, depending on different IMF $B_{x}$ and $B_{y}$ conditions during northward IMF.
Many observations of the field-aligned currents associated with TPAs indicate the existence of upward and downward current sheet pairs. A model study of the relationship between the large-scale convection pattern and the transpolararc associated field-aligned currents was performed by 
Marklund and Blomberg (1991). They modelled cases with locally balanced upward and downward arc currents, as well as the case of a single upward current associated with the arc but not locally balanced. With locally balanced currents the effect on the convection pattern is localized, whereas an unbalanced arc current system leads to a modification of the convection pattern on the global scale. Satellites have observed all three current configurations (e.g. Frank et al., 1986; Menietti and Burch, 1987; Marklund et al., 1991; Obara et al., 1993; Blomberg and Marklund, 1993; Blomberg and Cumnock, 2004). In addition, as the IMF becomes more northward, both the Region 1 to Region 2 and the NBZ to Region 1 current ratios increase (e.g. Blomberg and Marklund, 1993).

The main purpose of this paper is to model the global potential patterns and to compare them to DMSP plasma observations during the evolution of dawnside and duskside originating transpolar arcs. Utilizing satellite data, the Royal Institute of Technology (KTH) model provides the highlatitude global potential pattern. For the first time we model the entire evolution of the theta aurorae. In both events the theta moves across the entire polar region and becomes part of the opposite side of the auroral oval. During each event a variety of field-aligned current configurations is observed, associated with the changing global aurora.

\section{Observations}

\subsection{Interplanetary magnetic field data}

In Fig. 1 we show magnetic field data from the ACE (Advanced Composition Explorer) satellite which orbits the L1 Lagrange point about $200 R_{E}$ sunward of the Earth. IMF GSM components are plotted for our two examples, with 8 November 1998 at the top and 11 February 1999 at the bottom, as a function of corrected universal time (UT plus the estimated propagation time from the satellite to GSM $X=0$ ); in the top panel (8 November 1998) the correction is about $45 \mathrm{~min}$ and in the bottom panel (11 February 1999) about $1 \mathrm{~h}$. The thickest vertical line in each plot marks the time when the TPA is aligned along the noon-midnight meridian. The three additional lines mark the time when the DMSP F13 satellite reaches its highest magnetic latitude over the Northern Hemisphere during each orbit. The thick horizontal line at the top of each panel denotes the time period of UVI data shown in Figs. 2 and 3. Data are also available from the Wind satellite and show very similar IMF measurements (even though for 11 February 1999 Wind is at GSM $Y=-70)$.

In the first event ( 8 November 1998) IMF $B_{z}$ is positive for at least $3 \mathrm{~h}$ prior to and following a change in $B_{y}$. IMF $B_{x}$ is negative throughout the time period of interest. In the second event (11 February 1999) IMF $B_{z}$ is less stable, it is positive on average for about $3 \mathrm{~h}$ prior to the change in $B_{y}$, then there are two brief southward excursions before and three brief sharp decreases in $B_{z}$ after the $B_{y}$ change occurs.
Also, during 11 February 1999 IMF $B_{z}$ is less than $\left|B_{y}\right|$, except when $B_{y}$ is changing sign. IMF $B_{x}$ and $B_{y}$ are anticorrelated and thus consistent with a Parker spiral orientation. In both events $B_{y}$ is small for 1 to $1.5 \mathrm{~h}$ while changing sign.

ACE plasma measurements for 8 November 1998 (not shown) indicate that during the time of the IMF $B_{y}$ change, solar wind ion density is about $20 \mathrm{~cm}^{-3}$ and solar wind velocity is about $550 \mathrm{~km} / \mathrm{s}$. For 11 February 1999, solar wind ion density is about $30 \mathrm{~cm}^{-3}$ and solar wind velocity is about $430 \mathrm{~km} / \mathrm{s}$.

\subsection{Polar UVI data}

The Ultraviolet Imager (UVI) experiment (Torr et al., 1995) on the Polar spacecraft provides global images of the aurora. Polar was launched on 24 February 1996 into an 86-deg inclination orbit, with an apogee of $9 R_{E}$ in the Northern Hemisphere, and a perigee of $1.8 R_{E}$. The UVI experiment is one of four instruments mounted on a despun platform which can be oriented along one axis. The UV imager, with an 8deg field-of-view (FOV), can image the entire auroral oval above 60-deg north latitude at spacecraft altitudes greater than $6 R_{E}$. The instrument is able to resolve $0.5 \mathrm{deg}$ in latitude at apogee; thus, a single pixel projected to $100 \mathrm{~km}$ altitude from apogee is approximately $50 \times 50 \mathrm{~km}$.

Spacecraft wobble causes some blurring of the image pixels. In the first event (8 November 1998), the instrument is in sync mode (3-s integration), greatly minimizing, if not eliminating the effect. In the second event (11 February 1999) the wobble occurs along the 09:00-21:00 magnetic local time (MLT) meridian causing some distortion noticeable in the TPA when it is at highest latitudes. In the Lyman-BirgeHopfield mode (LBH) the instrument measures molecular nitrogen emissions in the 140-160 nm spectral region.

On 8 November 1998 Polar UVI provides images in the Northern Hemisphere taken with the LBH short (LBHs) filter at a 3-s integration period, giving a lower signal-to-noise ratio but a negligible effect from satellite wobble. In this event the transpolar arc originates on the duskside of the auroral oval and migrates across the entire polar region. Falsecolour images of the aurora are shown in Fig. 2, with a $\log$ colour scale extending from 0.4 to $4.5 \mathrm{kR}$. Images are plotted in magnetic apex latitude (Richmond, 1995) and magnetic local time. In this event the TPA is clearly seen, although portions of the evening and duskside oval are not in the imager FOV. Images have been selected to illustrate theta aurora development at different stages, beginning at 12:47 UT. The duskside of the auroral oval has expanded poleward, as expected for positive $B_{z}$ and positive $B_{y}$, and has a bright poleward edge. At 13:08 UT there are some enhancements of, and distortions in, the nightside portion (about 23:00 MLT) of the TPA. IMF $B_{y}$ changes sign from positive to weakly negative at about 14:00 UT, then decreases about $12 \mathrm{nT}$ at about 14:45 UT. IMF $B_{x}$ is negative and $B_{z}$ remains positive (ranging from 13-26nT for the next $9 \mathrm{~h}$ ). During the next hour (14:00 to 15:00 UT) the TPA moves dawnward. At 

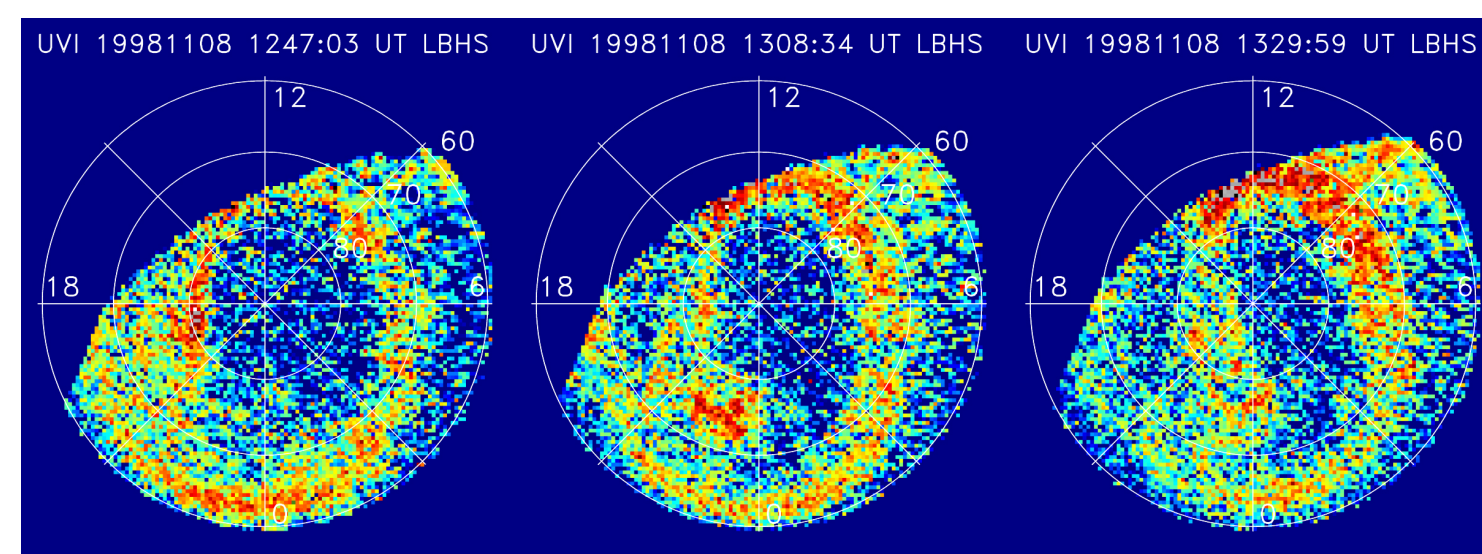

UVI 19981108 1348:23 UT LBHS

UVI 19981108 1409:48 UT LBHS
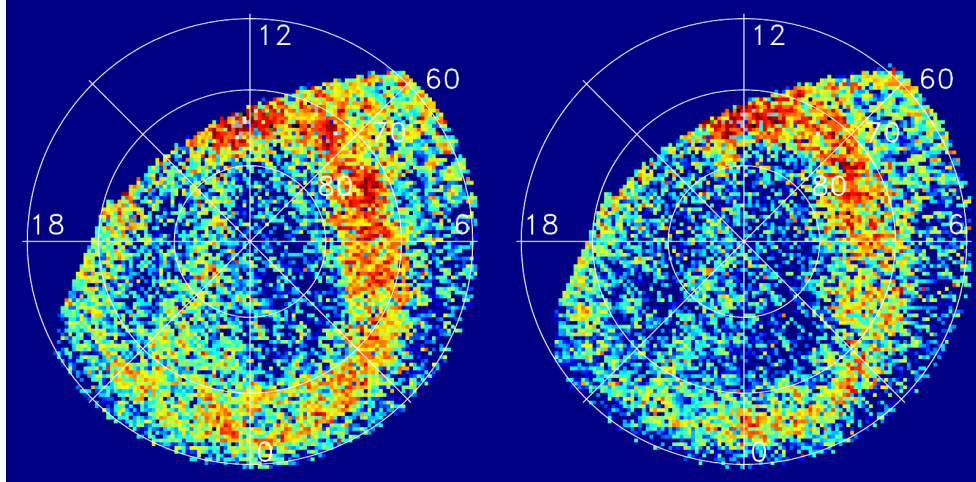

UVI 19981108 1428:13 UT LBHS

UVI 19981108 1446:38 UT LBHS

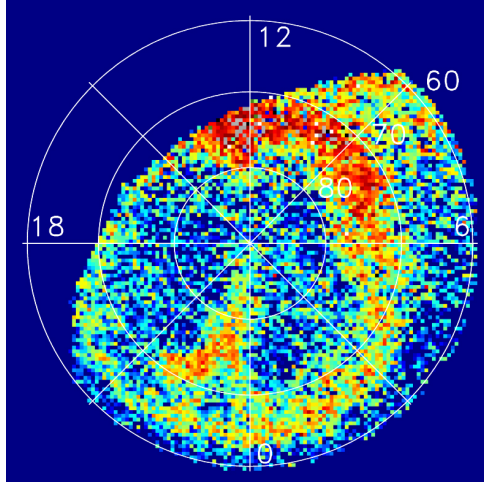

UVI 19981108 1501:56 UT LBHS
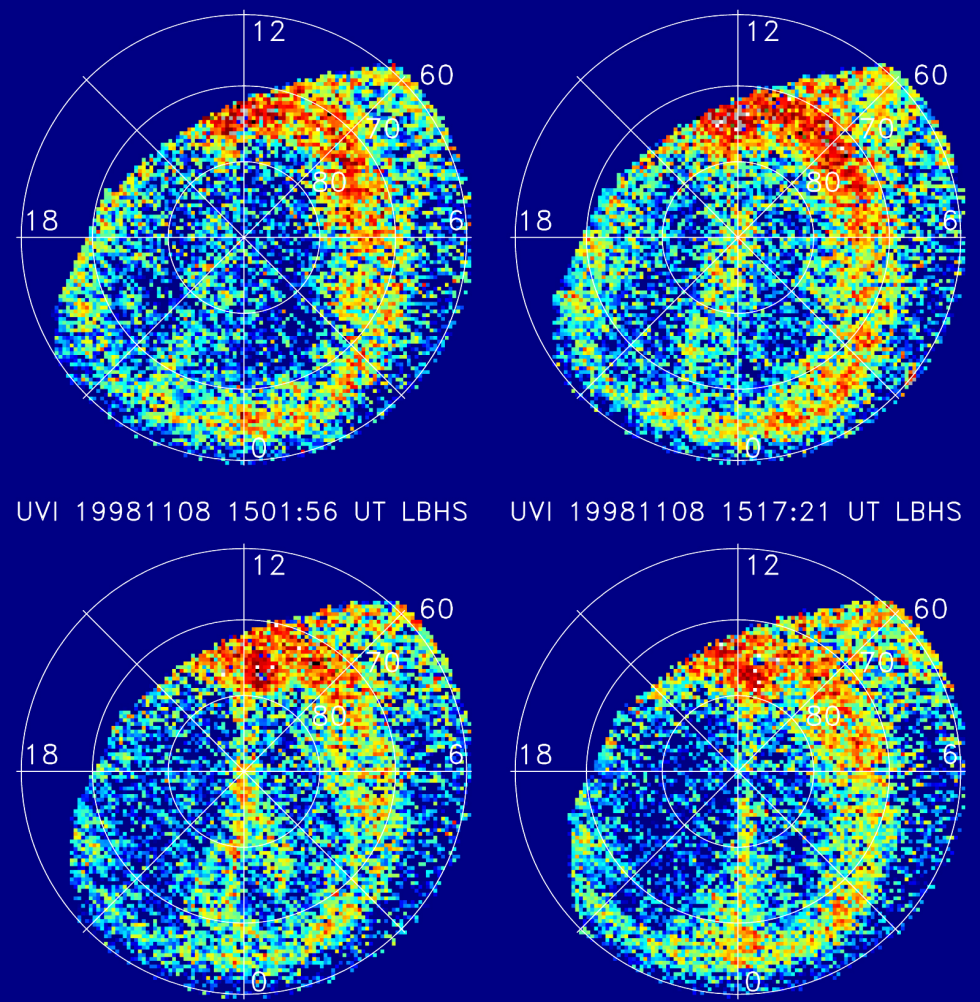

UVI 19981108 1517:21 UT LBHS

UVI 19981108 1532:40 UT LBHS

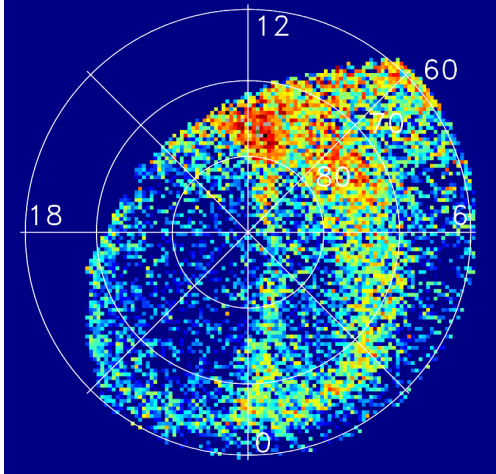

UVI 19981108 1551:04 UT LBHS
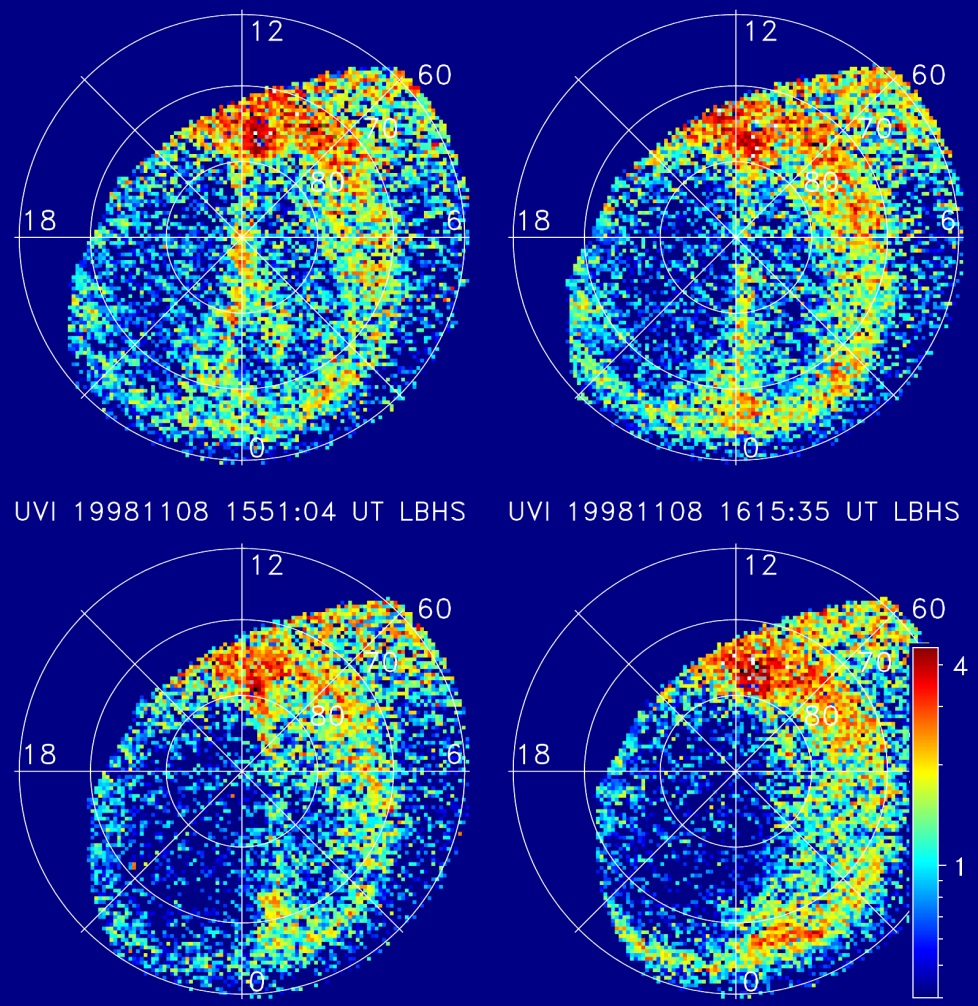

UVI 19981108 1615:35 UT LBHS

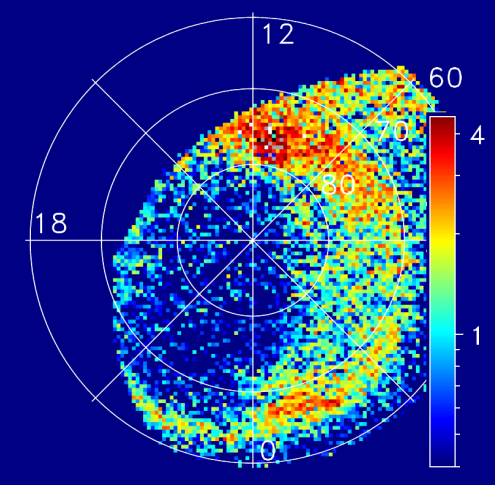

Fig. 2. On 8 November 1998, the Polar UVI instrument provides images in the Northern Hemisphere taken with the LBHs filter at a 3-s integration period and plotted in magnetic apex latitude and magnetic local time. False colour images of the aurora are shown, with a log colour scale extending from 0.4 to $4.5 \mathrm{kR}$. See text for details. 


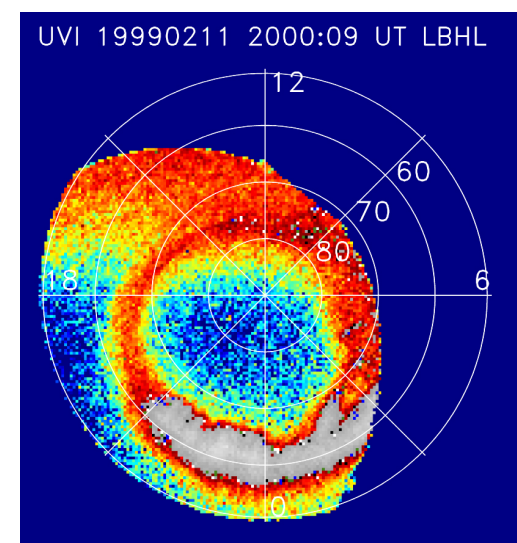

UVI 19990211 2100:16 UT LBHL

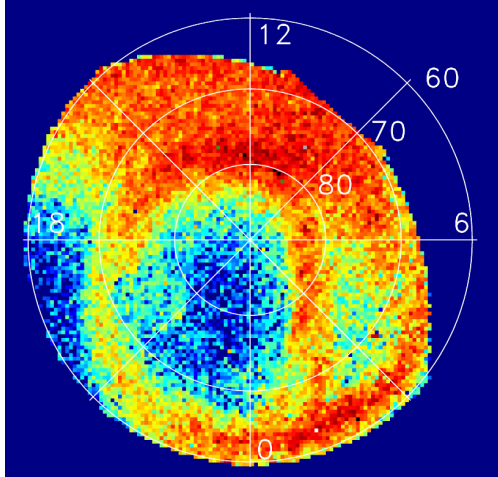

UVI 19990211 2200:22 UT LBHL

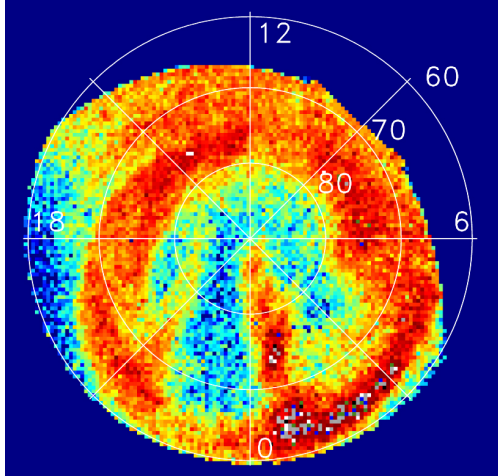

UVI 19990211 2300:28 UT LBHL

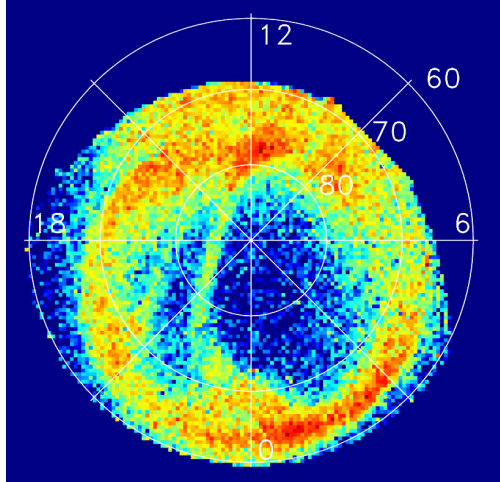

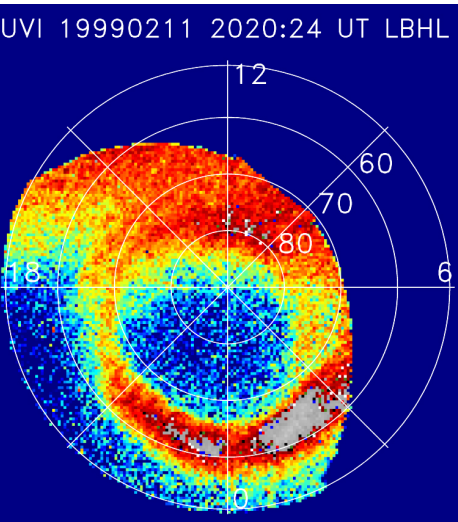

UVI $199902112120: 30$ UT LBHL

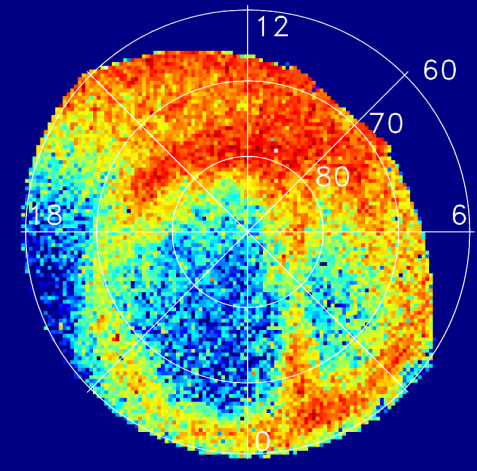

UVI 19990211 2220:00 UT LBHL

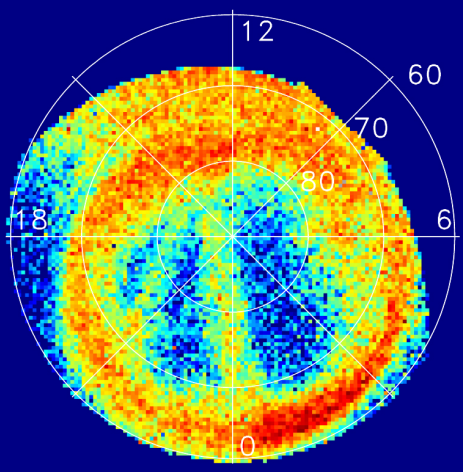

UVI 19990211 2330:32 UT LBHL

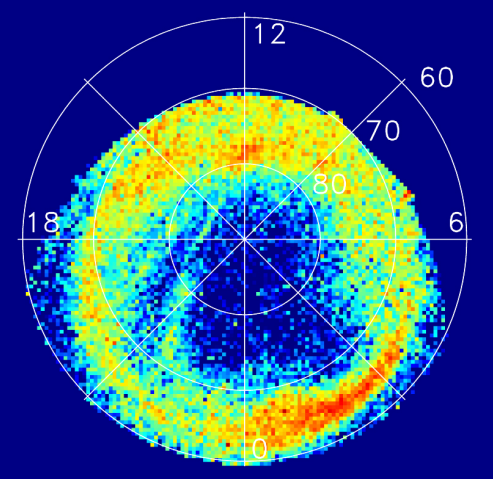

UVI 19990211 2040:01 UT LBHL

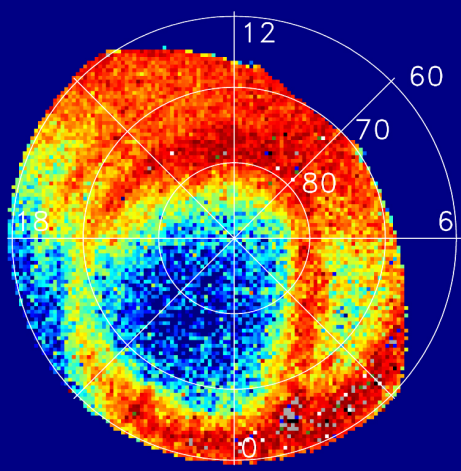

UVI 19990211 2140:08 UT LBHL

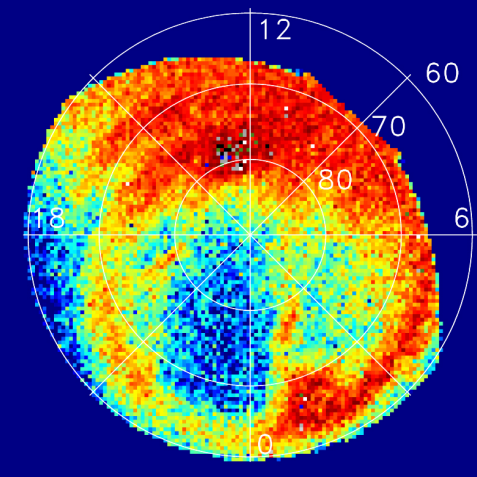

UVI 19990211 2240:14 UT LBHL

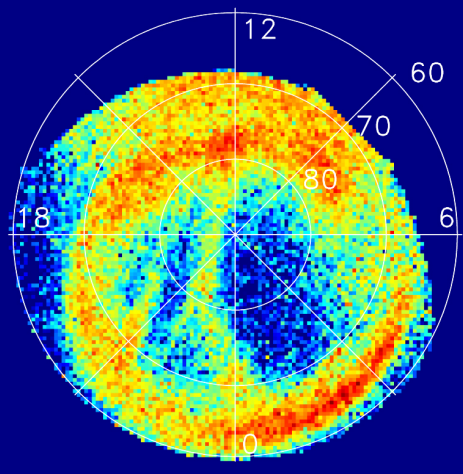

UVI 19990212 0045:21 UT LBHL

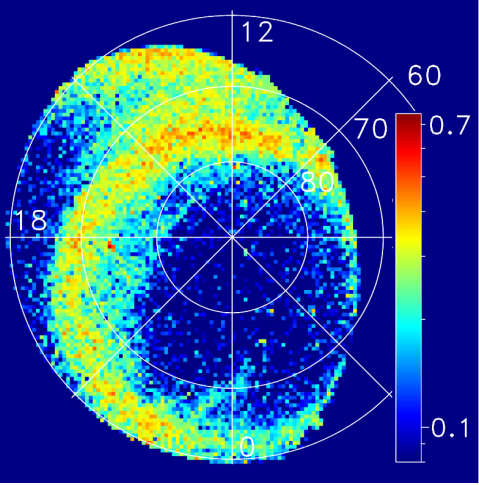

Fig. 3. For 11 February 1999, the Polar UV imager was in a mode that produced 36.8-s integration period images in the Northern Hemisphere using the LBHl filter and plotted in magnetic apex latitude and magnetic local time. False colour images of the aurora are shown, with a log colour scale extending from 0.08 to $0.75 \mathrm{kR}$. See text for details. 
14:46 UT the nightside portion of the TPA has split, forming an inverted $\mathrm{Y}$ shape where it joins the nightside auroral oval. In the image taken at 15:01 UT, about $1 \mathrm{~h}$ after $B_{y}$ becomes negative/near zero and about $15 \mathrm{~min}$ after $B_{y}$ becomes more strongly negative, the transpolar arc has moved to highest latitudes and is aligned along the noon-midnight meridian, forming a theta aurora. Note that the TPA is still split on the nightside. The dawnside of the auroral oval has expanded poleward, as expected for negative $B_{y}$. The arc continues its dusk to dawn motion and by 16:15 UT has moved across the polar region and appears to be part of the dawnside auroral oval.

For 11 February 1999 the UV imager was in a mode that produced 36.8-s integration period images in the Northern Hemisphere, using the LBH long (LBHl) filter. In this event the transpolar arc originates on the dawnside of the auroral oval and migrates across the entire polar region. False-colour images of the aurora are shown in Fig. 3, with a log colour scale extending from 0.08 to $0.75 \mathrm{kR}$. A portion of the dawnside oval is not in the imager FOV until midway through the time period of interest. Throughout the time period of interest substorm-like activity is seen in the UV images that may be due to small southward excursions of $B_{z}$. Between about 19:15 and 20:00 UT (not shown) the dawnside of the auroral oval expands poleward, as expected for negative $B_{y}$ and positive $B_{z}$. Between about 20:00 and 21:30 UT, $B_{y}$ is weakly positive while changing sign from negative to positive. During this time the TPA appears to begin separating from the dawnside auroral oval (see image at 20:20 UT) and is clearly separated by 20:40 UT. As expected for positive $B_{y}$, the duskward migration of the TPA is accompanied by a poleward expansion of the duskside oval (21:40 UT). In this case an arc forms at the poleward edge of the duskside auroral oval and appears to separate by 22:00 UT. Only if $B_{y}$ were to change from positive to negative would this arc cross to the dawnside oval. The sharp decrease in IMF $B_{z}$ $(21 \mathrm{nT})$ and increase in $B_{y}(14 \mathrm{nT})$ at 21:30 UT may have triggered the substorm-like activity on the nightside or the auroral oval seen in images 21:40 and 22:00 UT. It appears to enhance the nightside portion of the TPA. At 22:20 UT the arc is aligned along the noon-midnight meridian, about $140 \mathrm{~min}$ after $B_{y}$ becomes positive/near zero and about an hour after $B_{y}$ becomes more strongly positive. At 22:40 UT the TPA is located just on the duskside of the noon-midnight meridian and is clearly attached to the dayside auroral oval. By 00:45 UT on 12 February 1999 the dawn originating TPA has merged with the duskside oval.

\subsection{DMSP data}

The Defense Meteorological Satellite Program's (DMSP) satellites provide measurements of precipitating particles and ionospheric plasma flows from three Northern Hemisphere passes during each of the two time periods of interest. DMSP F13 passes in the dusk-to-dawn direction and DMSP F14 from about 21:00 MLT to 10:00 MLT in the Northern Hemisphere. The SSJ/4 instrument package includes curved plate electrostatic analysers to measure electrons and ions from $32 \mathrm{eV}$ to $30 \mathrm{keV}$ at a rate of one complete electron and ion spectrum per second. The special sensor for ions, electrons, and scintillation (SSIES) provides measurements of the horizontal plasma flow and ion density at a rate of 6 samples per s. Figures 4 through 9 show at the top the F13 horizontal plasma flows perpendicular to the satellite track plotted over a UV image taken at the time F13 is at highest latitudes. In addition, F14 plasma flows are shown in Figs. 4, 5 and 6. The F13 spectrogram (lower panel) includes, from top to bottom, (1) electron and ion integral energy flux, (2) electron and ion average energy, (3) precipitating electron spectrogram, (4) precipitating ion spectrogram, and (5) cross-track horizontal plasma drift. In Fig. 1 vertical lines mark the times when the DMSP F13 satellite reaches highest latitudes. The electrostatic potential distribution, shown in Fig. 12, is derived by integrating the electric field $(\mathbf{E})$ along the satellite track, utilizing $\mathbf{E}=-\mathbf{v} \times \mathbf{B}$, where $\mathbf{v}$ is the measured transverse ion drift velocity and $\mathbf{B}$ is the model geomagnetic field. The electrostatic potential can then be used to determine which regions of sunward and antisunward flow may be connected by equipotential flow lines.

\subsection{November 1998}

Figure 4 shows data from the first DMSP orbit available from the UVI data period. The data shown occur during positive $B_{y}$ and northward IMF. DMSP F13 shows a spatially expanded duskside region of sunward flow which is bifurcated by a small antisunward flow region. This pattern has three sunward and two antisunward flow regions, producing four convection reversal boundaries (CRBs), where for southward IMF two CRBs are expected. The high-latitude convection pattern is dominated by sunward flow, some of which can be closed in the dawnside antisunward flow region, producing clockwise (negative potential) circulation in a cell located at highest latitudes on the dawnside of the polar region. The sunward flow associated with the TPA (12:24:12-12:25:05 UT, marked by vertical lines) may be closed in the antisunward flow region equatorward, resulting in a local maximum in the negative potential region. In addition to an expanded duskside sunward flow region during positive $B_{z}$ and $B_{y}$, we expect an expanded duskside auroral oval. The DMSP F13 spectrogram shows an expanded duskside oval, and Polar UVI also indicates an expanded oval, although part of the afternoon portion of the auroral oval is not in the imager FOV. DMSP data show that at the highest latitude portion of the duskside oval (at about $80 \mathrm{deg}$ magnetic latitude (MLAT)) the electron and ion spectra are those of a transpolar arc, but the energy flux is more typical of the oval and average energy is increasing. These arc signatures (from about 12:24:12-12:25:05 UT) are collocated with the duskside of the high-latitude sunward flow region. Poleward of the high-latitude arc signature is a spatially broad region of open field lines identified by polar rain in the electron data and a lack of ion precipitation. 


\section{UVI 981108 1228:38 UT LBHS}

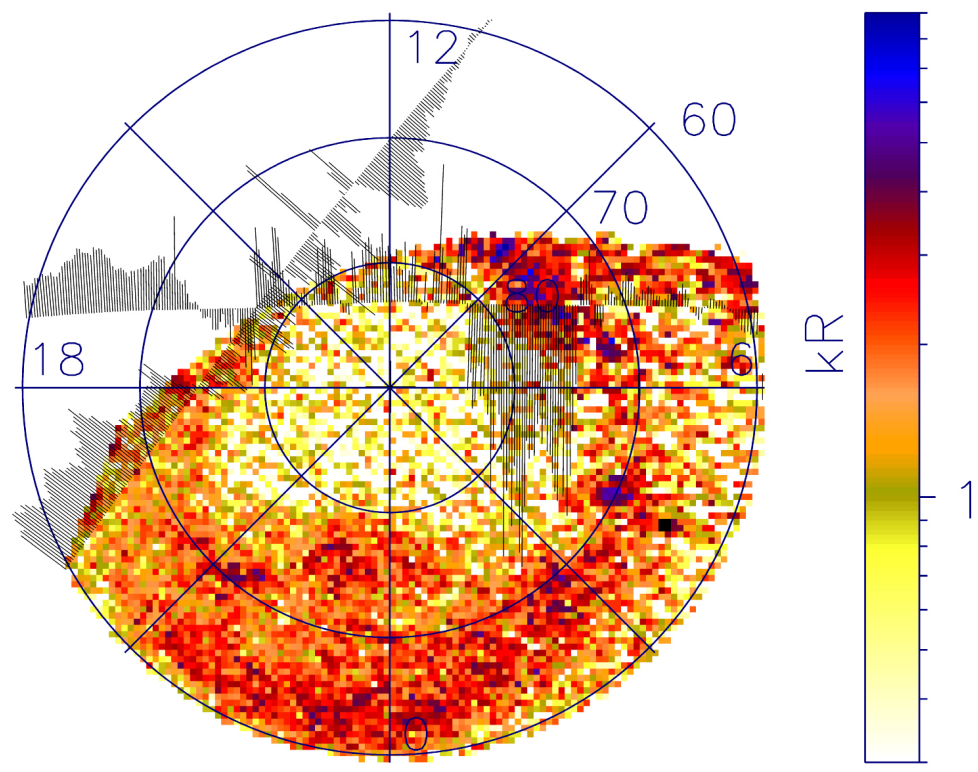

F13 8 Nov 1998

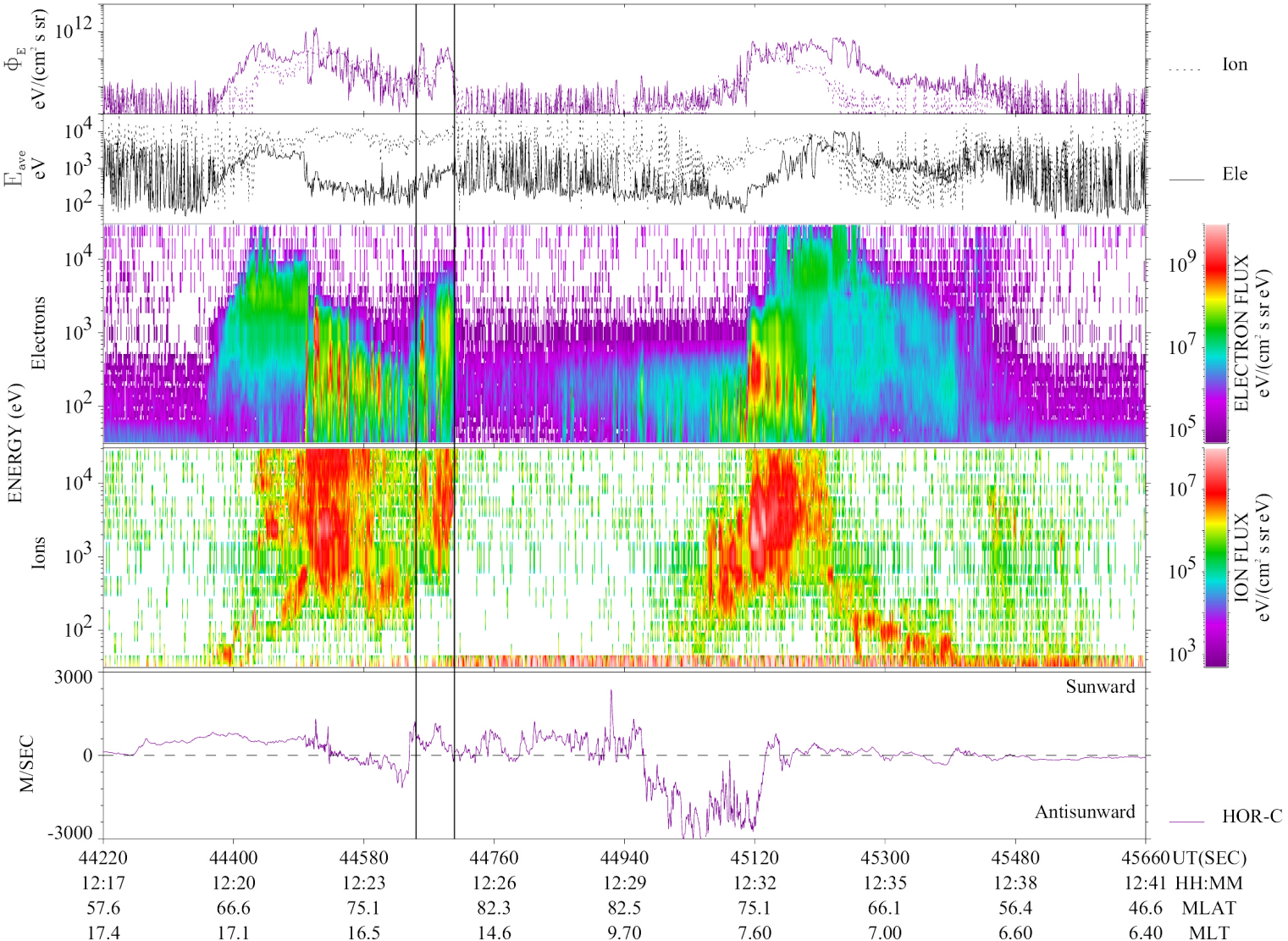

Fig. 4. Data shown from the first DMSP pass on 8 November 1998 (12:17-12:41 UT) that occurs during the Polar UVI data period. At the top are the F13 and F14 horizontal plasma flows, perpendicular to the satellite track plotted over a UV image taken at the time F13 is at highest magnetic latitudes. The F13 spectrogram (lower panel) includes, from top to bottom, (1) electron and ion integral energy flux, (2) electron and ion average energy, (3) precipitating electron spectrogram, (4) precipitating ion spectrogram, and (5) cross-track horizontal plasma drift. See text for details. 


\section{UVI 981108 1409:48 UT LBHS}

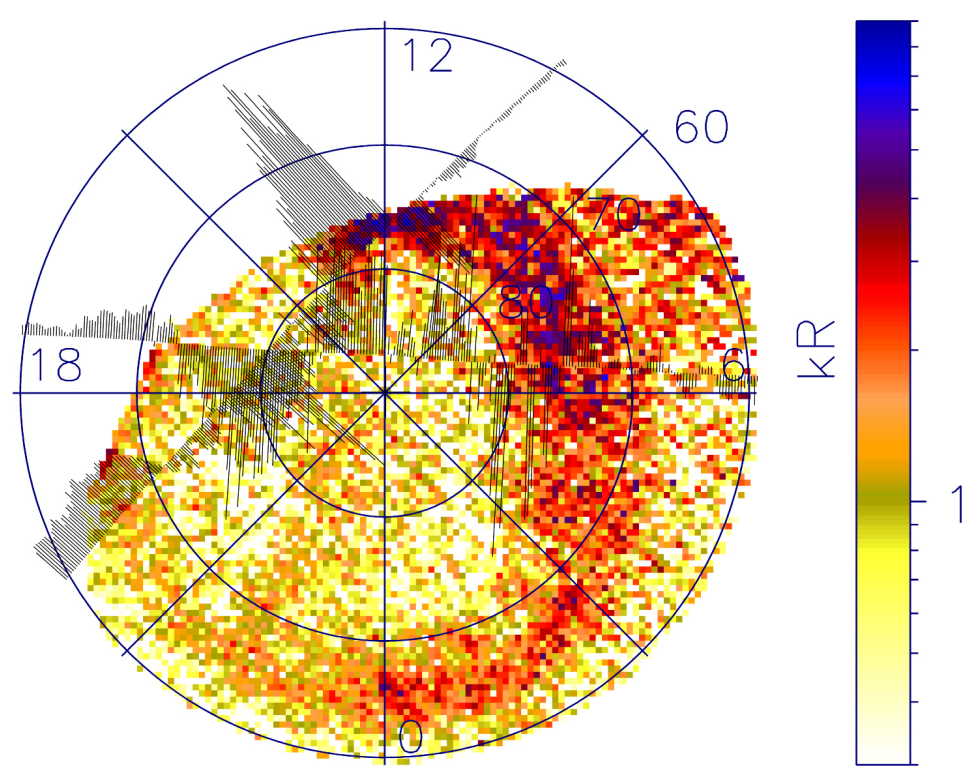

F13 8 Nov 1998
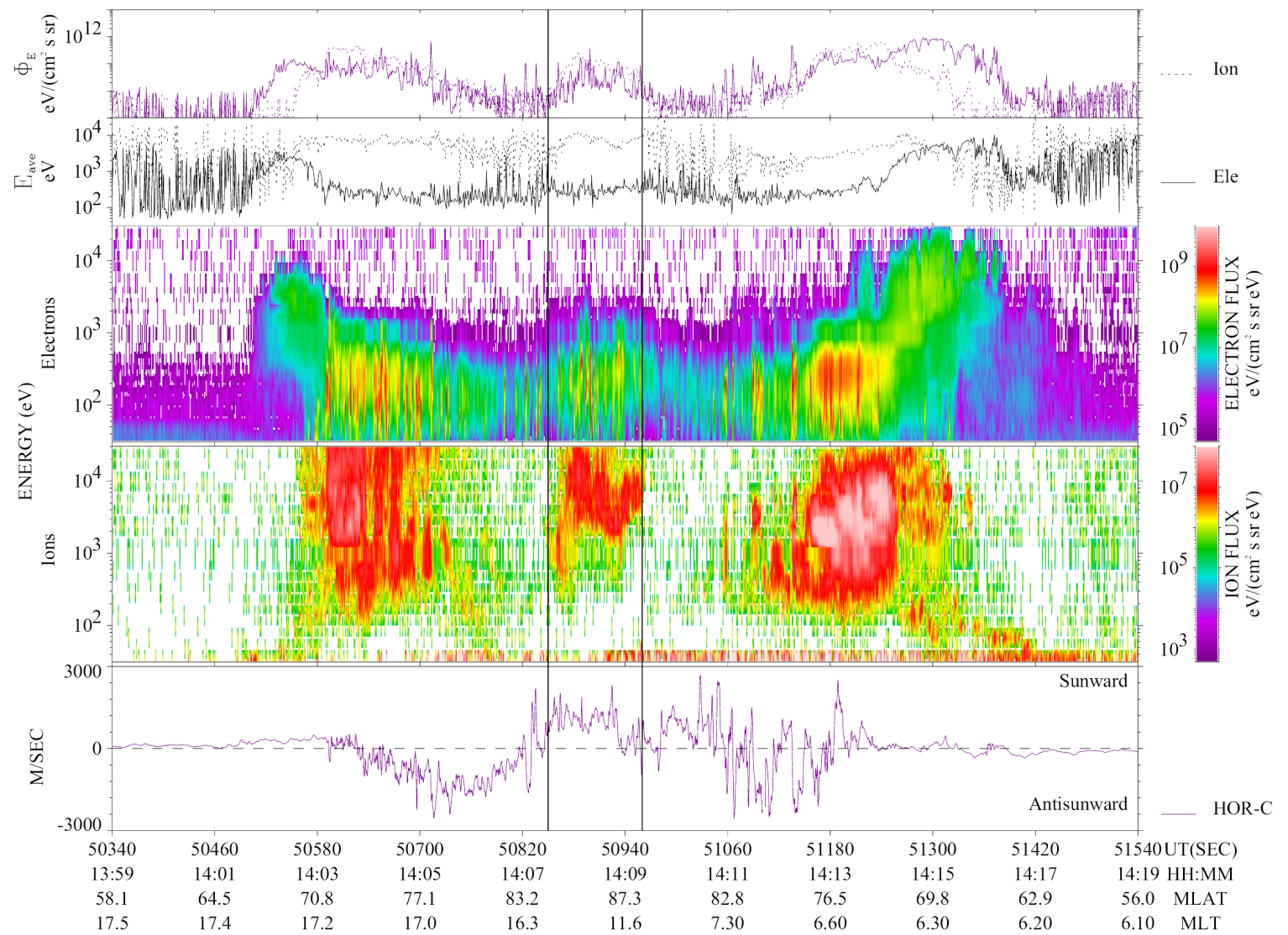

Fig. 5. Data shown from the second DMSP pass on 8 November 1998 (13:59-14:19 UT) that occurs during the UVI data period. Same format as Fig. 4. See text for details. 


\section{UVI 981108 1551:04 UT LBHS}

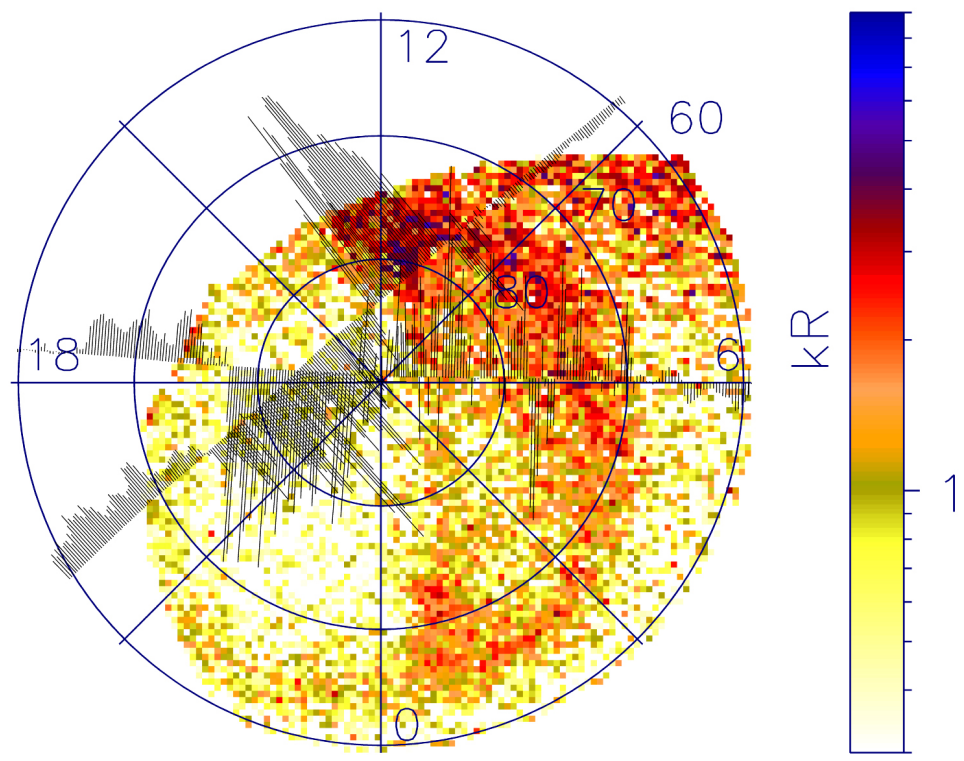

F13

8 Nov 1998

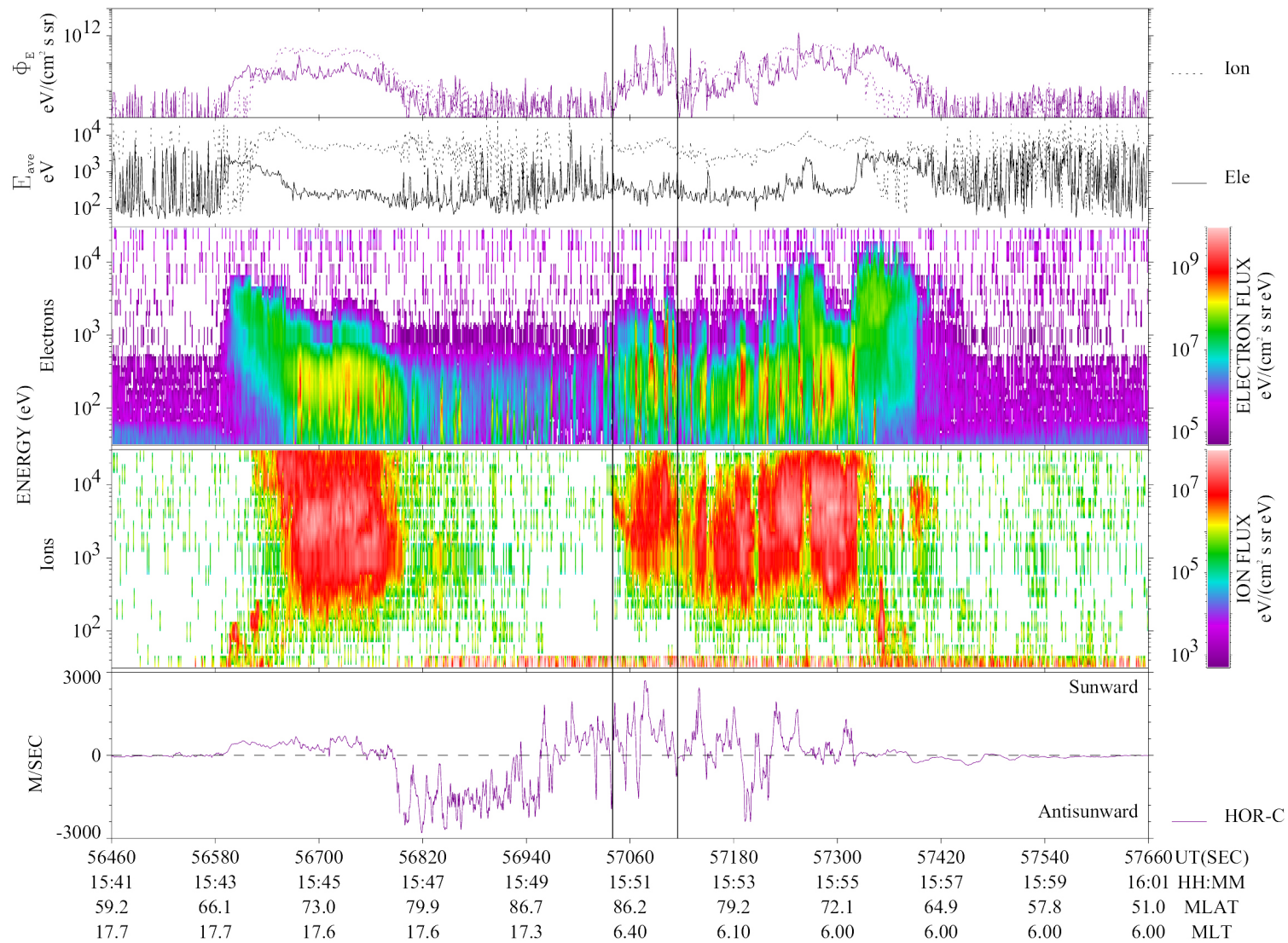

Fig. 6. Data shown from the third DMSP pass on 8 November 1998 (15:41-16:01 UT), which occurs during the UVI data period. Same format as Fig. 4. See text for details. 


\section{UVI 990211 1957:05 UT LBHL}

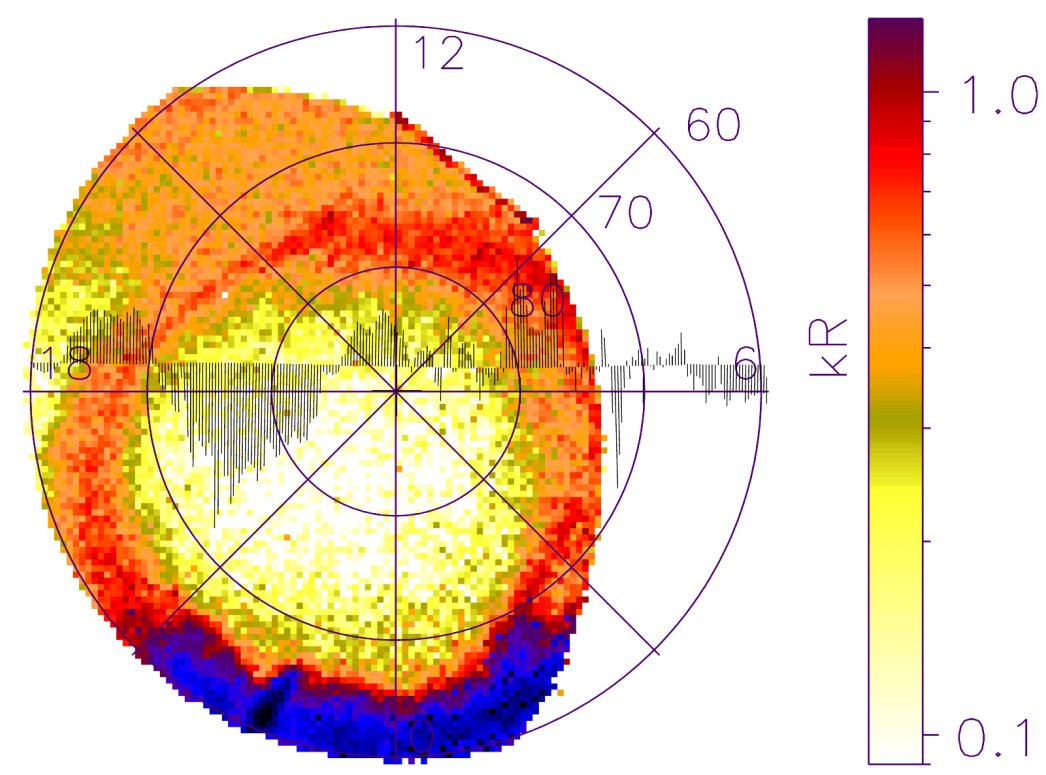

F13

11 Feb 1999

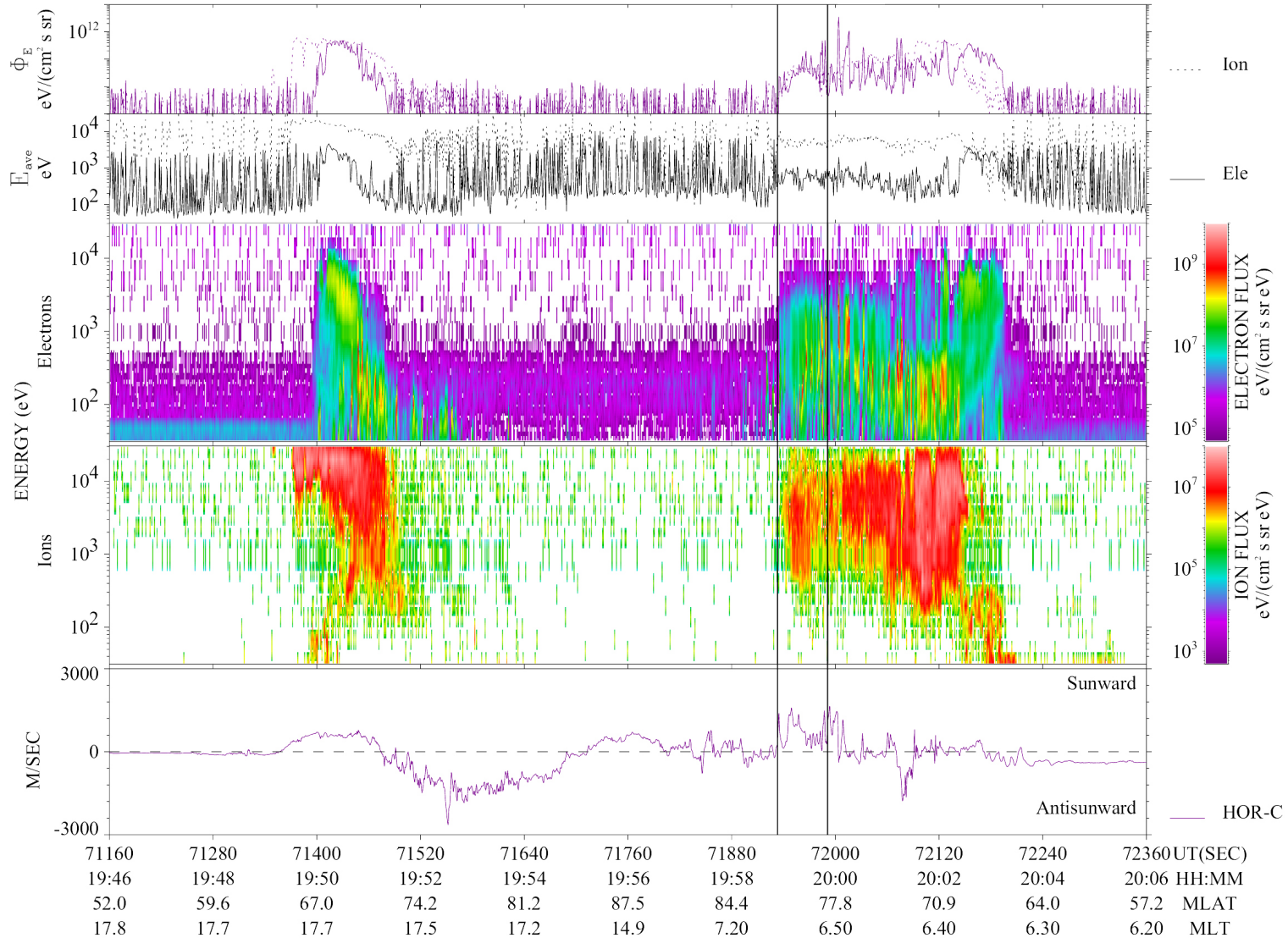

Fig. 7. Data shown from the first DMSP pass on 11 February 1999 (19:46-20:06 UT) that occurs during the Polar UVI data period. At the top are the F13 horizontal plasma flows, perpendicular to the satellite track plotted over a UV image taken at the time F13 is at highest magnetic latitudes. The F13 spectrogram (lower panel) includes, from top to bottom, (1) electron and ion integral energy flux, (2) electron and ion average energy, (3) precipitating electron spectrogram, (4) precipitating ion spectrogram, and (5) cross-track horizontal plasma drift. See text for details. 
By the time of the second DMSP pass, shown in Fig. 5, IMF $B_{y}$ has changed sign from positive to weakly negative. Both DMSP F13 and F14 reach higher magnetic latitudes than in the previous pass. On the dayside of the dawn-dusk meridian large antisunward and sunward flows are seen in what is traditionally the polar cap. Previously, the sunward flow was dominated by clockwise circulation (negative potential) in a dawn cell, whereas now it is dominated by counterclockwise circulation (positive potential) in a high-latitude dusk cell. The transpolar arc has moved to higher latitudes, and is still located on the duskside of the noon-midnight meridian. The arc remains collocated with the duskside of the high-latitude sunward flow region, and both are now at higher latitudes than in the previous pass. The spectrogram shows an unusually broad arc collocated with sunward flow (from about 14:07:30-14:09:20 UT) and the TPA seen in the UV image. The arc consists of an electron and ion signature (energy and flux) usually associated with the auroral oval (closed field lines) which is surrounded by regions void of ions and filled with polar rain electrons (associated with open field lines). This is consistent with the clear spatial separation of the higher energy flux associated with the TPA from that associated with the auroral oval.

At the time of the observations shown in Fig. 6, IMF $B_{z}$ is still positive and IMF $B_{y}$ has been negative (or weakly negative) for about $2 \mathrm{~h}$. Both DMSP satellites have reached higher magnetic latitudes than in the previous orbit, with the F13 satellite track aligned along the dawn-dusk meridian. The flow pattern now has two main CRBs, where the one located at highest latitudes is associated with a spatially expanded dawnside sunward flow region. The ionospheric convection pattern is still dominated by a counterclockwise circulating cell (positive potential) which is located at highest latitudes. The transpolar arc is now located on the dawnside of the noon-midnight meridian but is still collocated with the duskward edge of the high-latitude sunward flow region. The spectrogram shows the arc (from about 15:50:4015:51:55 UT) as part of an expanded dawnside, but associated with a peak in energy flux which is still separated from the peak of the energy flux associated with the auroral oval.

\subsection{February 1999}

Figure 7 shows data from a DMSP pass when IMF $B_{z}$ is northward, IMF $B_{y}$ is changing from negative to weakly positive and IMF $B_{x}$ is changing from positive to negative. DMSP F13 shows a spatially expanded dawnside region of sunward flow which is bifurcated by small antisunward flow regions. The sunward flow associated with the TPA (19:58:53-19:59:51 UT, marked by vertical lines) can be closed in the antisunward flow region equatorward, resulting in a local minimum in the positive potential region. This pattern is similar to the first pass of the previous example ( 8 November 1998), except that the expansion is from the dawnside, as expected for negative $B_{y}$. The high-latitude convection pattern is dominated by sunward flow, some of which can be closed in the duskside anti-sunward flow region, pro- ducing anti-clockwise (positive potential) circulation in a cell located at highest latitudes on the duskside of the polar region. The DMSP F13 spectrogram and Polar UVI show an expanded dawnside oval. DMSP data show that at the highest latitude portion of the dawnside oval (at about 81 deg MLAT) the electron and ion spectra are those of a transpolar arc (located at about 19:58:53-19:59:51 UT) which is collocated with the duskside of the lower latitude sunward flow region. The energy flux has increased but the arc signature is not separated from the oval, as was seen in Fig. 4. Poleward of the high-latitude arc signature is a spatially broad region of open field lines identified by polar rain in the electron data and a lack of ion precipitation.

By the time of the second DMSP pass, shown in Fig. 8, IMF $B_{y}$ has become more strongly positive. DMSP F13 passes at lower latitudes on the dayside than in the previous orbit. Convection is now dominated by clockwise circulation (negative potential), as expected for positive $B_{y}$. The TPA appears to have separated from the dawnside auroral oval and a second arc has formed at the poleward edge of the duskside auroral oval co-located with sunward plasma flow. DMSP F13 passes through the poleward edge of the dayside auroral oval, thus the spectrogram shows multiple arc structures throughout, making identification of the two arcs difficult.

By the last DMSP pass for this event, shown in Fig. 9, IMF $B_{z}$ is still positive and $B_{y}$ has been positive for about $3 \mathrm{~h}$. The dawnside originating TPA is now located on the duskside and has faded. DMSP F13 is located at lower magnetic latitudes than in the previous pass, passing again through the poleward edge of the dayside auroral oval. Spatially expanded duskside sunward flow can be closed in a strong antisunward flow region, resulting in a large clockwise circulating (negative potential) cell dominating the dayside region. The spectrogram shows a gap in the energetic particles at highest latitudes, apparently associated with the poleward edge of the auroral oval.

For both events TPA motion and convection are similar, although mirrored. However, for 11 February 1999 the UV emissions have a greater intensity and a second arc forms as the first TPA moves across the polar region. The differences in the two events may be due to the less steady IMF $B_{z}$ in the second event. Brief southward turnings would change the location of the anti-parallel merging region, thus disrupting reconnection, precipitating particles, and the growth of the plasma circulation associated with the TPA. In addition, during 11 February 1999 IMF $B_{x}$ is strongly positive until it changes to negative when IMF $B_{y}$ changes. During negative $B_{x}$ the IMF is in a more favourable orientation to be anti-parallel to the dayside lobe field lines.

\section{Modelled field-aligned currents and potential pat- terns}

In order to analyse the global potential patterns during theta aurora evolution we utilize the KTH numerical model which assumes a field-aligned current distribution and a 


\section{UVI $9902112138: 17$ UT LBHL}

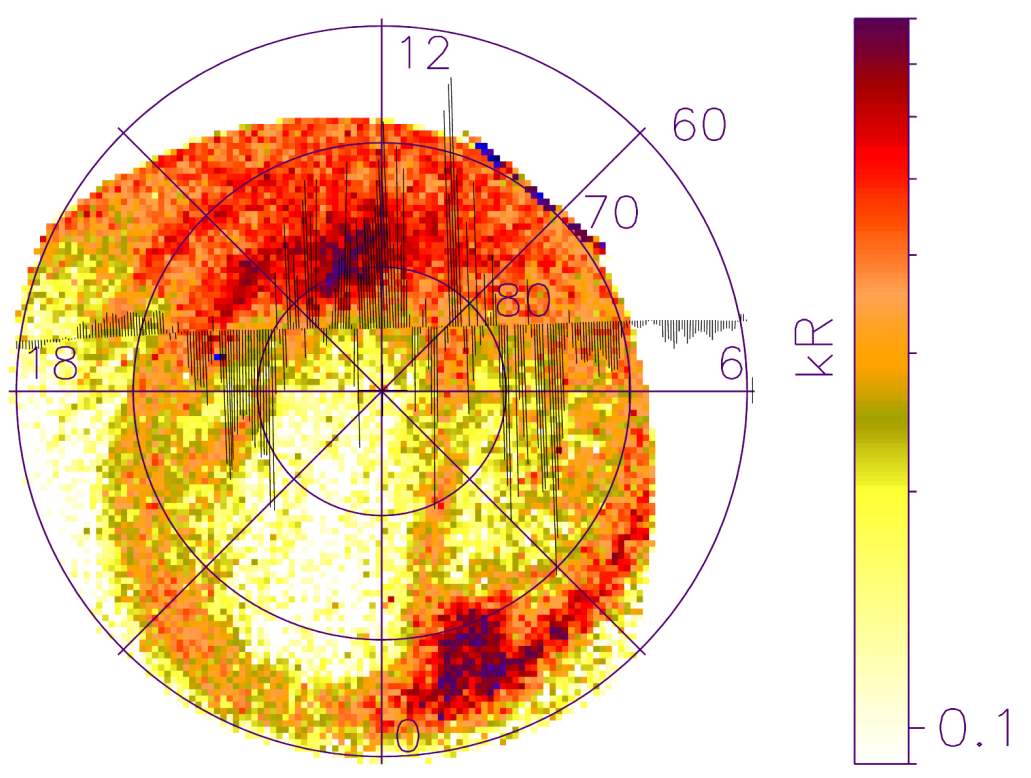

\section{F13 11 Feb 1999}

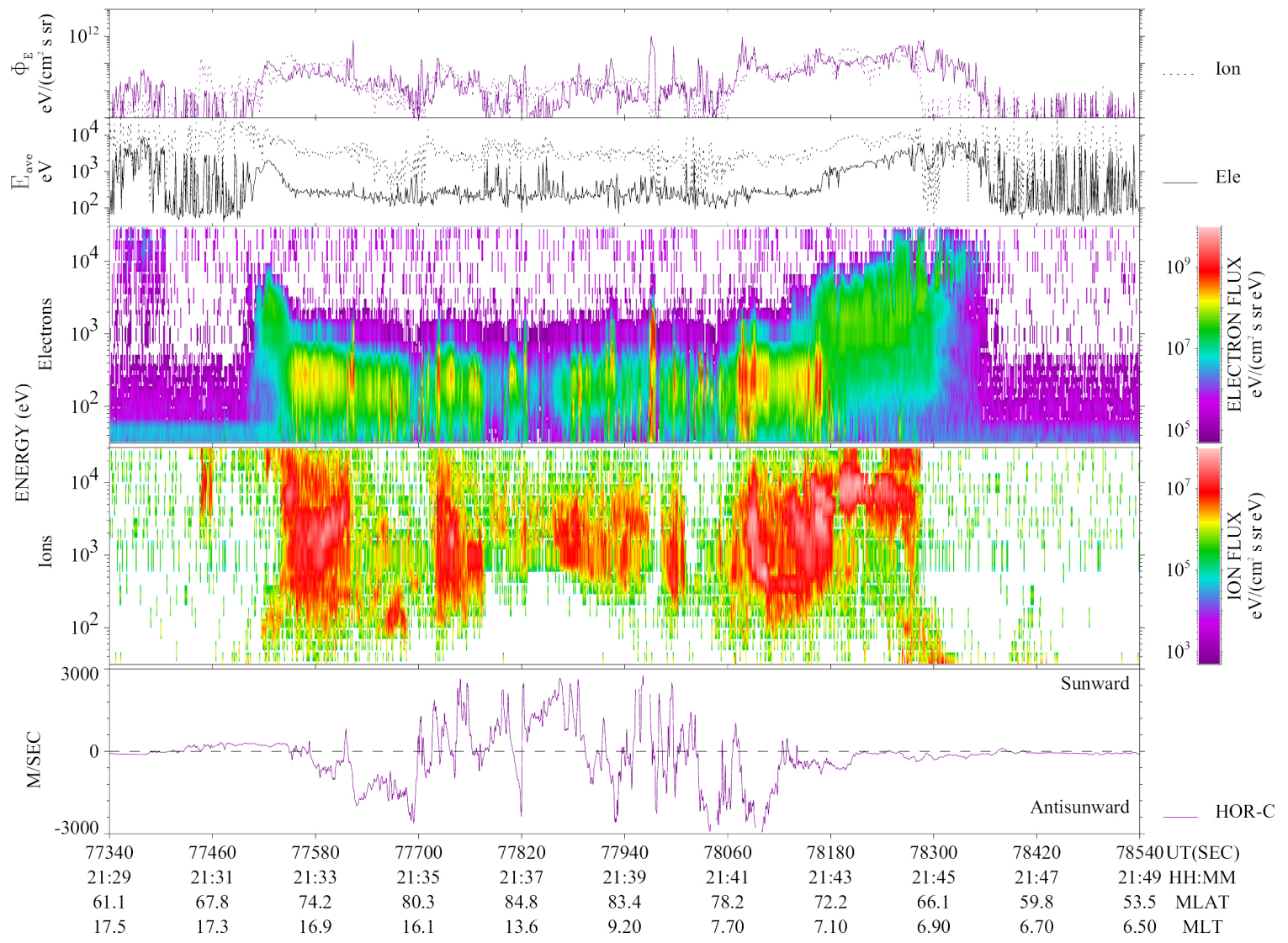

Fig. 8. Data shown from the second DMSP pass on 11 February 1999 (21:29-21:49 UT) that occurs during the UVI data period. Same format as Fig. 7. See text for details. 


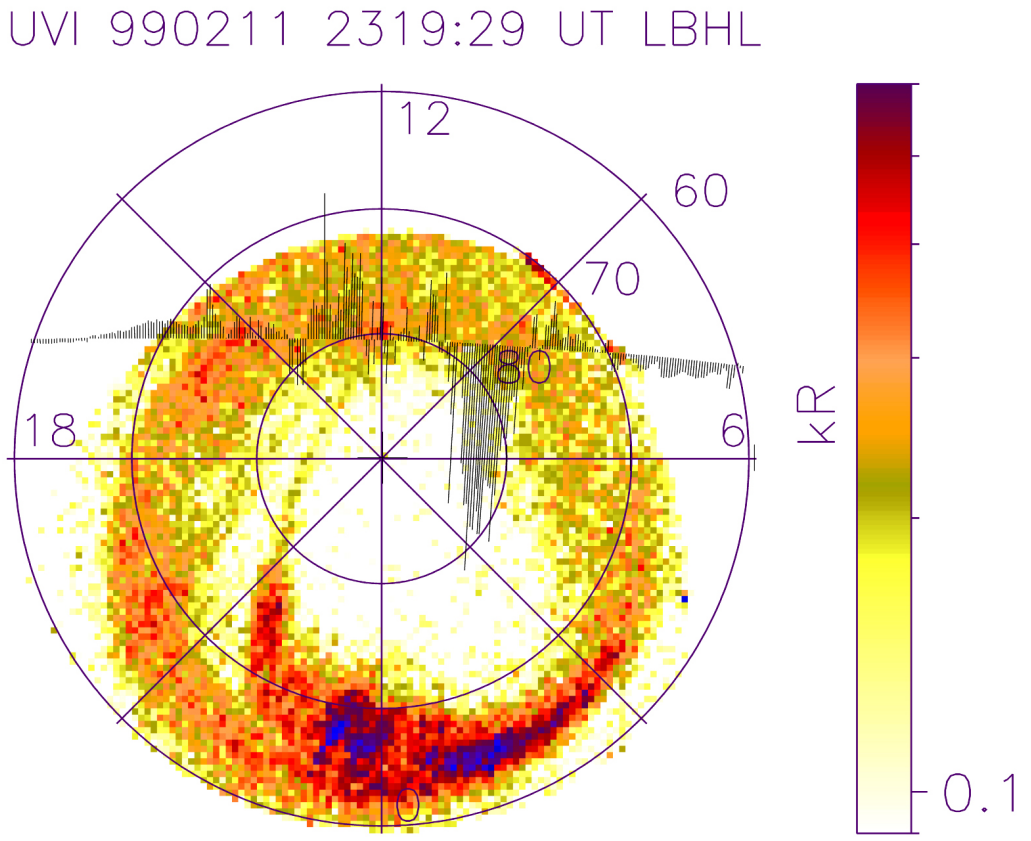

F13 11 Feb 1999

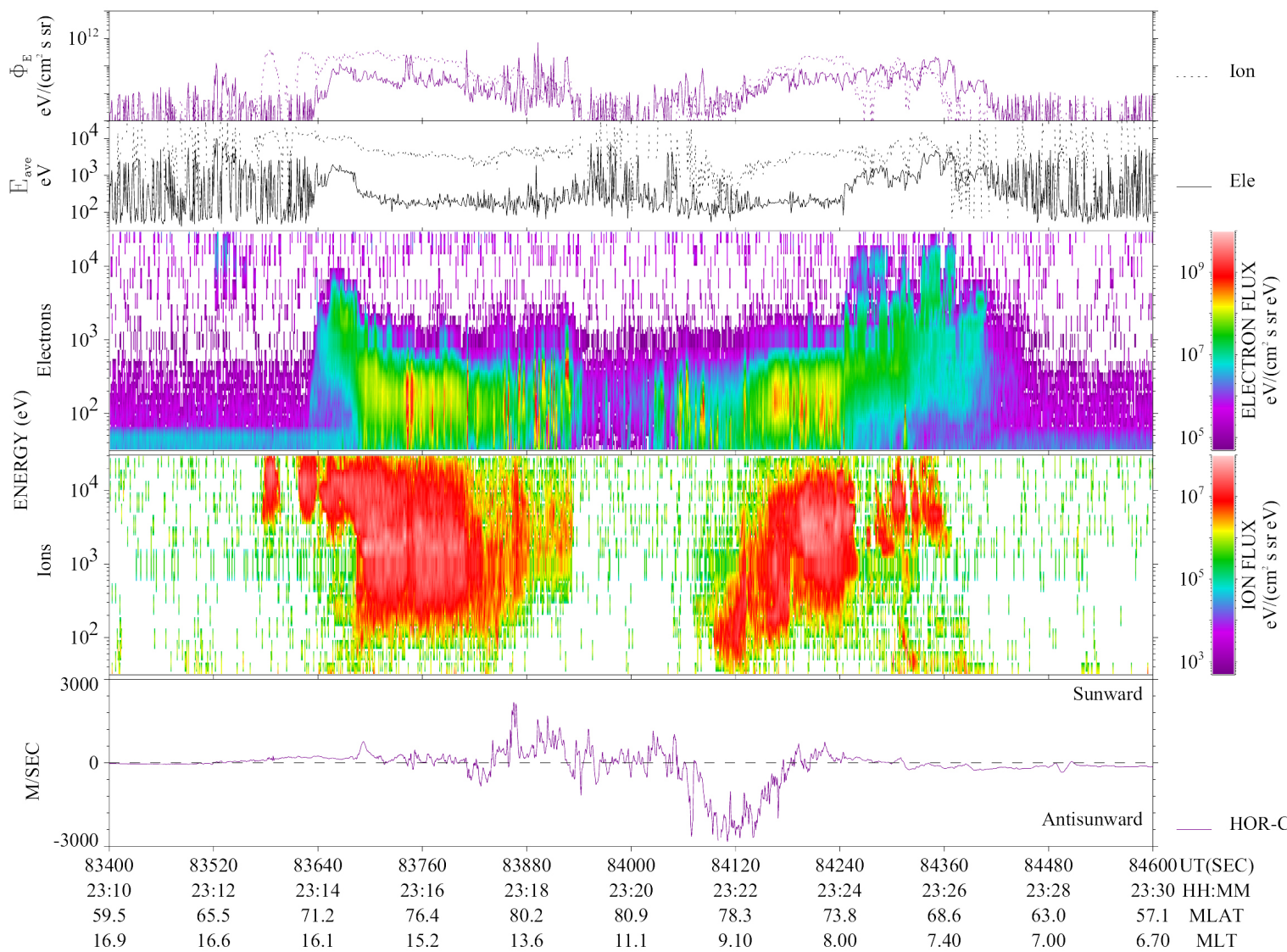

Fig. 9. Data shown from the third DMSP pass on 11 February 1999 (23:10-23:30 UT) that occurs during the UVI data period. Same format as Fig. 7. See text for details. 

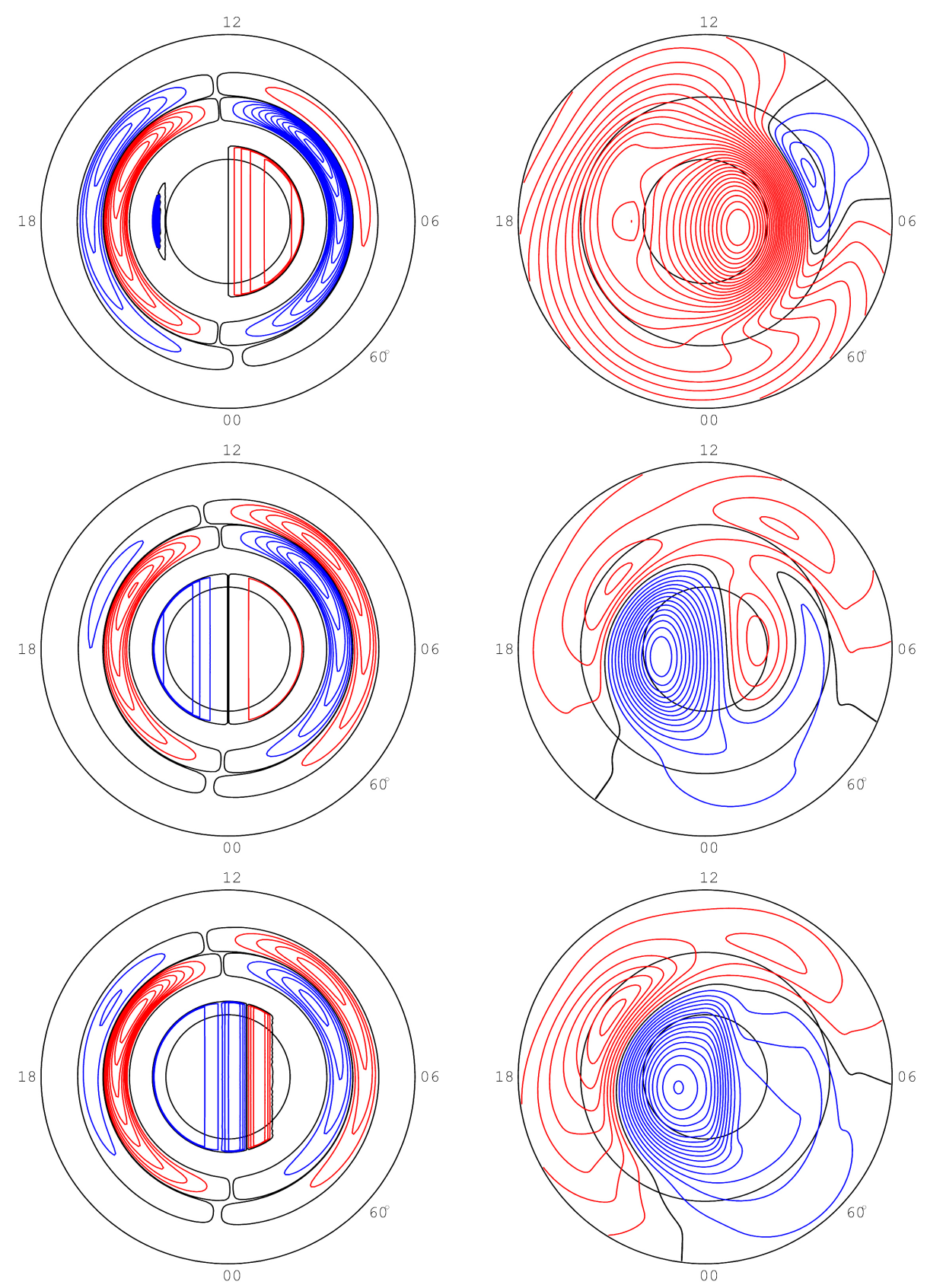

Fig. 10. Shown on the left, modelled field-aligned current patterns $\left(0.1 \mu \mathrm{A} / \mathrm{m}^{2}\right.$ contour separation) for each of the DMSP passes on 8 November 1998; and on the right, the electrostatic potential patterns ( $3 \mathrm{kV}$ contour separation) generated by the KTH model. Upward and downward FACs are shown in red and blue, respectively; positive potentials are shown in blue and negative in red. The black line denotes zero potential. See text for details.

conductivity model, and from these calculates the potential distribution. A detailed description of the model is found in Blomberg and Marklund (1991a). Applications of the model to event studies were presented, for example, by Marklund et al. (1987), and Marklund and Blomberg (1991). Earlier theoretical applications include Blomberg and Marklund (1991b).

The model input, the field-aligned current (FAC) distribution, is qualitatively inferred from satellite UV images, which give direct information about upward currents associated with electron precipitation. Downward currents are qualitatively inferred from statistical models. The currents can then be quantitatively calibrated directly against satellite magnetometer data, as well as indirectly calibrated by comparing the calculated model potential pattern to satellite plasma flow data in an iterative manner. Data from one or more satellites can be used for the calibration. The model takes into account that the energy spectrum of the downward 
field-aligned electron flow is softer on the dayside than on the nightside. In the mid-dawn and mid-dusk sectors there is a smooth transition between the high nightside and the low dayside conductivity values. Upward flowing particles usually have thermal energies and thus deplete rather than enhance the ionospheric ionisation, since they drain the system of charged particles without producing new free charges by collisional ionisation. Downward currents may contribute to the ionospheric ionisation through precipitation of protons associated with the diffuse aurora, with a small contribution to the total precipitated particle energy. Precipitating electrons may produce significant ionisation. The contribution of electron precipitation to the ionisation is particularly important in the dark winter ionosphere.

The goal here is to reconstruct on a global scale the distribution of all relevant electrodynamic parameters associated with the aurora which occur during the range of northward IMF conditions as a TPA moves across the entire polar region. Model inputs are the ionospheric conductivity and FAC distributions. The boundary condition used is that the potential is zero at 50 deg magnetic latitude, in reasonable agreement with DMSP data. Polar UVI provides information on the FAC distribution. Regions of upward FACs are located by assuming that the intensity of UV emitted from the atmosphere is proportional to the energy flux of the precipitating electrons and that the upward FAC density is proportional to the square root of the energy flux. This information is used to adjust statistical patterns of FACs and ionospheric conductivities. Then DMSP magnetometer data can be used to check the distributions of upward and downward FACs along the satellite track. DMSP particle data then can be used to calculate particle energy flux along the satellite track, assuming that conductivity enhancement due to the precipitating particles is proportional to the upward FACs. Model output is the ionospheric potential which can be compared with the potential calculated from electric field data along the DMSP satellite tracks. Finally, we iterate until good agreement is reached between model output and in-situ measurements.

Figure 10 shows on the left, model field-aligned current patterns for each of the DMSP passes on 8 November 1998; and on the right, the electrostatic potential patterns generated by the KTH model. Upward and downward FACs are shown in red and blue, respectively, positive potentials are shown in blue and negative in red. The black line denotes zero potential. Similar plots for 11 February 1999 are shown in Fig. 11. Table 1 lists the model input values for the FACs.

We see a variety of field-aligned current configurations associated with the changing global aurora for both events. TPA currents are localized, whereas for 11 February 1999 some of the return current is spread over a large area (NBZ current). In only the second plots of each event are there both upward and downward NBZ currents. The total TPA current is typically smaller than the NBZ current. However, because of the limited spatial extent of the TPA current, TPA current density is comparable to, or may be greater than, the NBZ current density. The maximum and minimum values of the electrostatic potentials are shown in Table 2.
Figure 12 shows line plots of the calculated electrostatic potentials, of both the DMSP F13 measurements (thick line) and the model (thin, smooth line), along the F13 satellite track. Plots on the left-hand side correspond to the three F13 satellite orbits (Figs. 4-6) and three potential plots (Fig. 10) for 8 November 1998; plots on the right correspond to 11 February 1999 (Figs. 7-9 and 11). As can be seen, there is good agreement between the model and the calculated potential variation along the DMSP satellite track. However, the model does not account for geometric differences in the auroral oval location, thus the patterns may be shifted (noticeable in the two lower plots).

Looking at the large-scale patterns shown in Figs. 10 and 11, we see on 8 November 1998 that the pattern changes from dominant negative potential to dominant positive potential, whereas on 11 February 1999 the reverse occurs. In both events the patterns change from a large cell (with a smaller cell corotating within) on one side of the auroral region to reverse convection and finally, a large cell dominating the opposite side of the auroral region. The dominant one-cell patterns, seen in the first and third plots of each event, result from NBZ currents which are not balanced (that is, either upward or downward currents, but not both). For positive potential (negative potential) downward (upward) NBZ currents dominate, as expected.

In both events the TPA current configuration consists of a pair of upward and downward FACs, with the upward current on the dawnside of the downward current. This configuration is consistent with Marklund and Blomberg (1991) Case 2. Whereas it is not expected that the TPA evolution should be symmetric for both dusk and dawn originating TPA, it is interesting that this configuration can exist for both dawn and dusk originating TPAs. Previously, Jankowska et al. (1990) show convection schematics, (in their Fig. 4, based on data presented by Elphinstone et al., 1990), similar to the first plot of each of our events. In both dawn and dusk originating cases the TPA is associated with sunward flow and upward current, which can be closed with downward current located duskward.

In the second plot of each event both upward and downward NBZ currents exist, and their magnitudes increase as the IMF becomes more northward, as expected (Iijima et al., 1984). The existence of both upward and downward NBZ currents results in two reverse convection cells at highest latitudes. Reverse convection may occur as two different convection configurations. Both configurations are seen in the second plot of our examples. 8 November 1998 shows reverse convection as part of a distorted two-cell pattern, 11 February 1999 shows it as separate cells at highest latitudes. Differences are also seen in the currents; in the second plot on 8 November 1998, Region 1 and Region 2 currents located on the dawnside are large compared to NBZ currents. However, in the second plot of 11 February 1999 NBZ currents dominate and Region 2 currents are very small.

Zanetti et al. (1990) analyse a single image similar to the early part of the TPA evolution seen on 11 February 1999. In their case a dawn originating TPA has moved only to about 

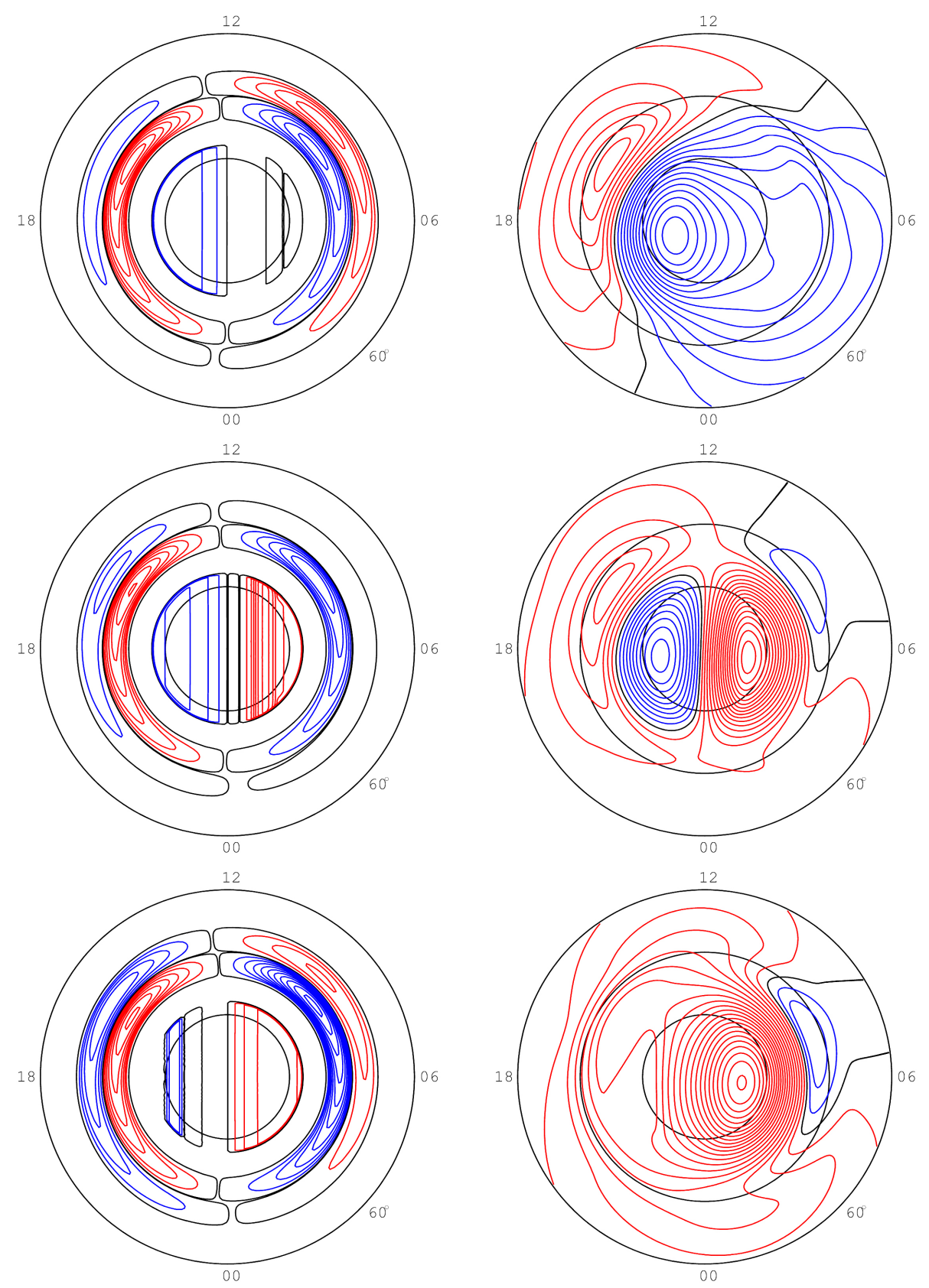

Fig. 11. Shows the modelled field-aligned currents and electrostatic potential patterns for 11 February 1999. Same format as Fig. 10.

Table 1. Modelled field-aligned current values (MA).

\begin{tabular}{l|cc|cccc|cc}
\hline Event & \multicolumn{2}{|c|}{ Dusk } & \multicolumn{4}{c}{ Polar Region } & \multicolumn{2}{c}{ Dawn } \\
\hline & $\mathrm{R} 2 \downarrow$ & $\mathrm{R} 1 \uparrow$ & $\mathrm{NBZ} \downarrow$ & $\mathrm{TPA} \downarrow$ & $\mathrm{TPA} \uparrow$ & $\mathrm{NBZ} \uparrow$ & $\mathrm{R} 1 \downarrow$ & $\mathrm{R} 2 \uparrow$ \\
\hline 8 Nov. 1998-1 & 0.50 & 0.72 & & 0.06 & 0.005 & 0.85 & 1.05 & 0.20 \\
8 Nov. 1998-2 & 0.15 & 0.55 & 0.55 & 0.10 & 0.05 & 0.30 & 0.60 & 0.60 \\
8 Nov. 1998-3 & 0.23 & 0.80 & 0.55 & 0.30 & 0.27 & & 0.40 & 0.50 \\
\hline 11 Feb. 1999-1 & 0.20 & 0.69 & 0.52 & 0.01 & 0.02 & & 0.50 & 0.50 \\
11 Feb. 1999-2 & 0.25 & 0.64 & 0.63 & 0.10 & 0.23 & 0.60 & 0.55 & 0.10 \\
11 Feb. 1999-3 & 0.55 & 0.65 & & 0.12 & 0.02 & 0.70 & 0.95 & 0.35 \\
\hline
\end{tabular}



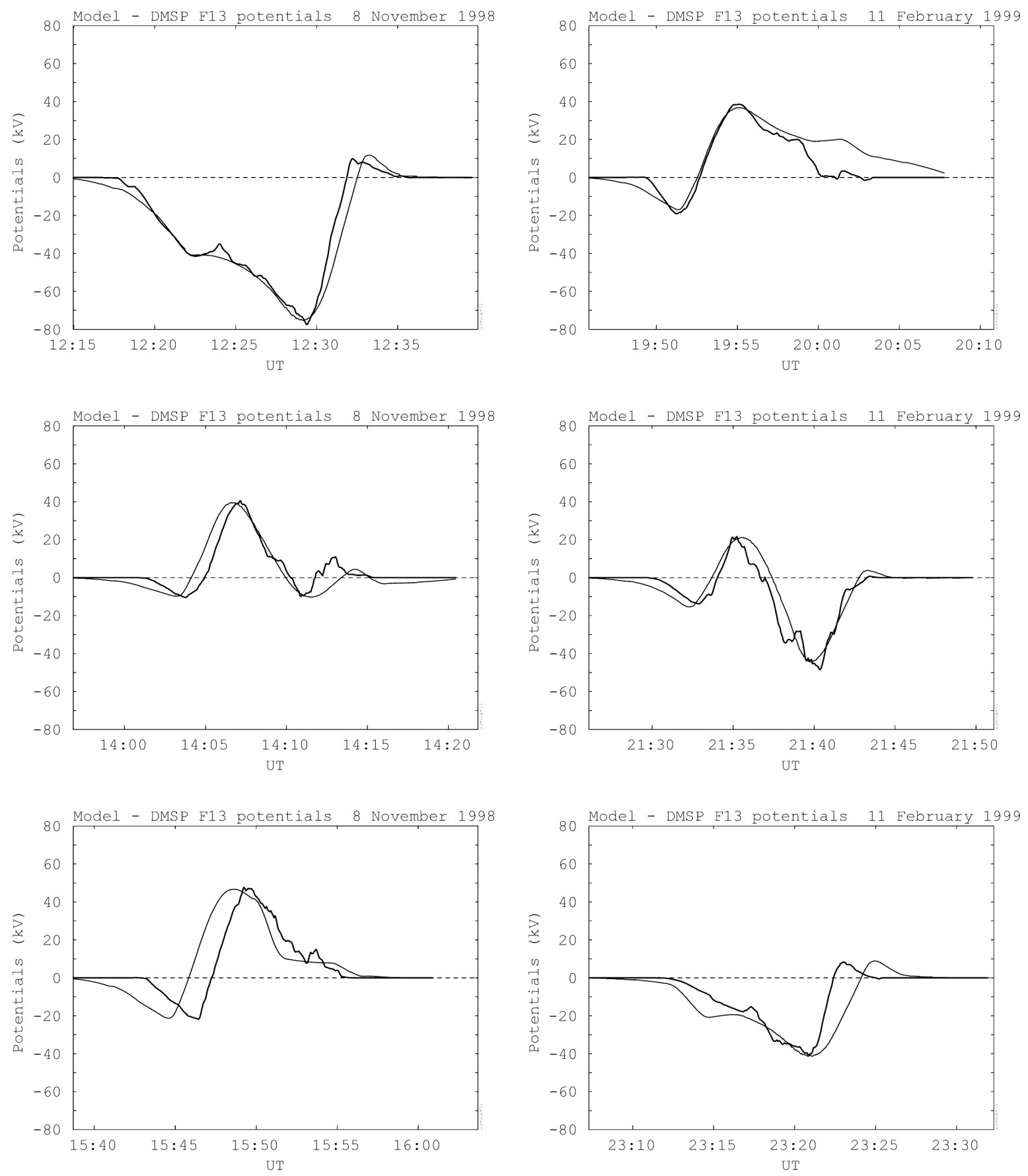

Fig. 12. Shown are the calculated electrostatic potentials of both the DMSP F13 measurements (thick line) and the model (thin, smooth line), along the F13 satellite track. Plots on the left-hand side correspond to the three F13 satellite orbits (Figs. 4 through 6) and three potential plots (Fig. 10) for 8 November 1998; plots on the right correspond to 11 February 1999 (Figs. 7 through 9 and 11).

80 deg MLAT, this is probably due to $B_{y}$ changing from negative to near zero (but not positive). Even though the TPA does not move above $80 \mathrm{deg}$, the convection pattern evolves into a 4-cell pattern similar to the one in Fig. 11 (second row). They both have strong, nearly balanced NBZ currents and very small Region 2 currents. The TPA is embedded in the dawn NBZ current in both events.
Throughout the evolution of the theta aurora the TPA is collocated with the same part of the plasma flow pattern. The duskside (dawnside) originating arc is collocated with the duskward (dawnward) portion of the high-latitude sunward flow region, even as this region moves dawnward (duskward). Thus, the TPA is embedded in the same potential region, in a negative potential cell (or local minimum) for 
Table 2. Local potential extrema $(\mathrm{kV})$.

\begin{tabular}{l|c|cc|c}
\hline Event & Dusk & $\begin{array}{c}\text { Noon-midnight } \\
\text { Meridian }\end{array}$ & Dawn \\
\hline 8 Nov. 1998-1 & -45 & & -90 & +13 \\
8 Nov. 1998-2 & -13 & +45 & 11 & +5 \\
8 Nov. 1998-3 & -25 & +48 & & +9 \\
\hline 11 Feb. 1999-1 & -20 & +41 & & +20 \\
11 Feb. 1999-2 & -17 & +29 & -53 & +5 \\
11 Feb. 1999-3 & -20 & & -63 & +9 \\
\hline
\end{tabular}

a theta originating on the dawnside of the auroral region and in a positive potential cell (or local maximum) for the theta originating on the duskside. The large-scale nature of the convection cell associated with the transpolar arc suggests that transpolar arcs are a global phenomenon rather than a localized feature moving across the high-latitude region.

\section{Summary and conclusions}

In this paper we have attempted to reconstruct the ionospheric electrodynamical state associated with the evolution of theta aurora originating from both the dawn and the dusk sides of the auroral oval. To accomplish this, two unique northward IMF events are studied for which satellite observations were input into a global numerical model. Good agreement is obtained between the model and the calculated potential variation along the DMSP satellite track. Valuable experience is gained on how different electrodynamical parameters are related to each other in the global context.

The TPA (associated with closed field lines) originates as part of the dawn or dusk side auroral oval. As it moves to higher latitudes it is surrounded by regions void of ions and filled with polar rain electrons (associated with open field lines). The TPA then continues to move across the polar region and becomes part of the opposite oval from where it originated. This separation implies a highly distorted and dynamic magnetotail configuration.

In both events the TPA current configuration consists of a pair of upward and downward FACs with the upward current on the dawnside of the downward current. The TPA is embedded in the same region of sunward flow (and electrostatic potential), thus the TPA moves with the convection cell as it evolves. This indicates that the TPA is a global phenomenon.

Dawnside (duskside) formation of the TPA and duskward (dawnward) motion occurs when $B_{y}$ changes from negative to positive (positive to negative). During the evolution the TPA is embedded in a negative (positive) potential cell (or local minimum/maximum).

Balanced NBZ currents result in reverse convection at highest latitudes. If the NBZ currents dominate the Region 1 and Region 2 currents, a four-cell pattern results, otherwise, a distorted two-cell pattern is formed.
Acknowledgements. The authors thank George Parks for providing Polar UVI data and Fred Rich for providing the DMSP F13 and F14 SSIES and SSJ4/4 data. We thank the ACE MFI, ACE SWEPAM, Wind MFI, and Wind SWE instrument teams for providing magnetometer and plasma data through the CDAWeb. Work at the University of Texas at Dallas was supported by NSF Grants ATM9814144 and ATM0211572. Work at the Royal Institute of Technology was supported by the Swedish National Space Board.

Topical Editor T. Pulkkinen thanks a referee for his help in evaluating this paper.

\section{References}

Blomberg, L. G. and Marklund, G. T.: A numerical model of ionospheric convection derived from field-aligned currents and the corresponding conductivity, Rep. TRITA-EPP-91-03, Royal Inst. of Technology, Stockholm, 1991a.

Blomberg, L. G. and Marklund, G. T.: High-latitude convection patterns for various large-scale field-aligned current configurations, Geophys. Res. Lett., 18, 717, 1991 b.

Blomberg, L. G. and Marklund, G. T.: High-latitude electrodynamics and aurorae during northward IMF, in: Auroral Plasma Dynamics, Geophys. Monogr. Ser., 80, edited by Lysak, R. L., 5568, AGU, Washington, D. C., 1993.

Blomberg, L. G. and Cumnock, J. A.: Electrodynamics of transpolar aurorae, Adv. Space Res., in press, 2004.

Bythrow, P. F., Burke, W. J., Potemra, T. A., Zanetti, L. J., and Lui, A. T. Y.: Ionospheric evidence for irregular reconnection and turbulent plasma flows in the magnetotail during periods of northward interplanetary magnetic field, J. Geophys. Res., 90, 5319, 1985.

Carlson, H. C., Heelis, R. A., Weber, E. J., and Sharber, J. R.: Coherent mesoscale convection patterns during northward interplanetary magnetic field, J. Geophys. Res., 93, 14 501, 1988.

Cumnock, J. A., Heelis, R. A., Hairston, M. R., and Newell, P. T.: High-latitude ionospheric convection patterns during steady northward interplanetary magnetic field, J. Geophys. Res., 100, $14537,1995$.

Cumnock, J. A., Sharber, J. R., Hairston, M. R., Heelis, R. A., and Craven, J. D.: Evolution of the global auroral pattern during positive IMF $B_{z}$ and varying IMF $B_{y}$ conditions, J. Geophys. Res., 102, $17489,1997$.

Cumnock J. A., Sharber, J. R., Heelis, R. A., Blomberg, L. G., Germany, G. A., Spann, J. F., and Coley, W. R.: Interplanetary magnetic field control of theta aurora development, J. Geophys. Res., 107, doi:10.1029/2001JA009126, 2002.

Eliasson, L., Lundin, R., and Murphree, J. S.: Polar cap arcs observed by the Viking satellite, Geophys. Res. Lett., 14, 451, 1987.

Elphinstone, R. D., Jankowska, K., Murphree, J. S., and Cogger, L. L.: The configuration of the auroral distribution for interplanetary magnetic field $B_{z}$ northward, 1, IMF $B_{x}$ and $B_{y}$ dependencies as observed by Viking, J. Geophys. Res., 95, 5791, 1990.

Frank, L. A., Craven, J. D., Burch, J. L., and Winningham, J. D.: Polar views of the Earth's aurora with Dynamics Explorer, Geophys. Res. Lett., 9, 1001, 1982.

Frank, L. A., Craven, J. D. , Gurnett, D. A., Shawhan, S. D., Weimer, D. R., et al.: The theta aurora, J. Geophys. Res., 91, 3177, 1986.

Gusev, M. G. and Troshichev, O. A.: Relation of sun-aligned arcs to polar cap convection and magnetic disturbances, Planet. Space Sci., 38, 1, 1990. 
Heelis, R. A., Reiff, P. H., Winningham, J. D., and Hanson, W. B.: Ionospheric convection signatures observed by DE 2 during northward interplanetary magnetic field, J. Geophys. Res., 91, 5817, 1986.

Heppner, J. P. and Maynard, N. C.: Empirical high-latitude electric field models, J. Geophys. Res., 92, 4467, 1987.

Hoffman, R. A., Heelis, R. A., and Prasad, J. A.: A sun-aligned arc observed by DMSP and AE-C, J. Geophys. Res., 90, 9697, 1985.

Hones Jr., E. W., Craven, J. D., Frank, L. A., Evans, D. S., and Newell, P. T.: The horse- collar aurora: A frequent pattern of the aurora in quiet times, Geophys. Res. Lett., 16, 37, 1989.

Iijima, T., Potemra, T. A., Zanetti, L. J., and Bythrow, P. F.: Large-scale Birkeland currents in the dayside polar region during strongly northward IMF: A new Birkeland current system, J. Geophys. Res., 89, 7441, 1984.

Jankowska, K., Elphinstone, R. D., Murphree, J. S., Cogger, L. L., and Hearn, D.: The configuration of the auroral distribution for interplanetary magnetic field $B_{z}$ northward, 2. Ionospheric convection consistent with Viking observations, J. Geophys. Res., 95, 5805, 1990 .

Makita, K., Meng, C.-I., and Akasofu, S.-I.: Transpolar auroras, their particle precipitation, and IMF $B_{y}$ component, J. Geophys. Res., 96, 14 085, 1991.

Marklund, G. T. and Blomberg, L. G.: On the influence of localized electric fields and field-aligned currents associated with polar arcs on the global potential distribution, J. Geophys. Res., 96, 13977, 1991.

Marklund, G. T., Blomberg, L. G., Potemra, T. A., Murphree, J. S., Rich, J. R., and Stasiewicz, K.: A new method to derive "instantaneous" high-latitude p J. S. otential distributions from satellite measurements including auroral imager data, Geophys. Res. Lett., 14, 439, 1987.

Marklund, G. T., Blomberg, L. G., Murphree, J. S., Elphinstone, R. D., Zanetti, L. J., Erlandson, R. E., Sandahl, I., de la Beaujardière, O., Opgenoorth, H., and Rich, F. J.: On the electrodynamical state of the auroral ionosphere during northward IMF: A transpolar arc case study, J. Geophys. Res., 96, 9567, 1991.
Meng, C.-I.: Polar cap arcs and the plasma sheet, Geophys. Res. Lett., 8, 273, 1981.

Menietti, J. D. and Burch, J. L.: DE 1 observations of theta aurora plasma source regions and Birkeland current charge carriers, J. Geophys. Res., 92, 7503, 1987.

Obara, T., Kitayama, M., Mukai, T., Kaya, N., Murphree, J. S., and Cogger, L. L.: Simultaneous observations of sun-aligned polar cap arcs in both hemispheres by EXOS-C and Viking, Geophys. Res. Lett., 15, 713, 1988.

Obara, T., Mukai, T., Hayakawa, H., Nishida, A., Tsuruda, K., and Fukunishi, H.: Akebono (EXOS D) observations of small-scale electromagnetic signatures relating to polar cap precipitation, J. Geophys. Res., 98, 11 153, 1993.

Peterson, W. K. and Shelley, E. E.: Origin of the plasma in a crosspolar cap auroral feature (theta aurora), J. Geophys. Res., 89, 6729, 1984.

Potemra, T. A., Zanetti, L. J., Bythrow, P. F., Lui, A. T. Y., and Iijima, T.: $B_{y}$-dependent convection patterns during northward interplanetary magnetic field, J. Geophys. Res., 89, 9753, 1984.

Reiff, P. H. and Burch, J. L.: IMF $B_{y}$-dependent plasma flow and Birkeland currents in the dayside magnetosphere, 2, A global model for northward and southward IMF, J. Geophys. Res., 90, 1595, 1985.

Richmond, A. D.: Ionospheric electrodynamics using magnetic apex coordinates, J. Geomagn. Geoelectr., 47, 191, 1995.

Robinson, R. M. and Mende, S. B.: Ionization and electric field properties of auroral arcs during magnetic quiescence, J. Geophys. Res., 95, $21111,1990$.

Torr, M. R., Torr, D. G., Zukic, M., Johnson, R. B., Ajello, J., Banks, P., Clark, K. Cole, K., Keffer, C., Parks, G., Tsurutani, B., and Spann, J.: A far ultraviolet imager for the international solar-terrestrial physics mission, Space Sci. Rev., 71, 329, 1995.

Zanetti, L. J., Potemra, T. A., Erlandson, R. E., Bythrow, P. F., Anderson, B. J., Murphree, J. S., and Marklund, G. T.: Polar region Birkeland currents, convection and aurora for northward interplanetary magnetic field, J. Geophys. Res., 95, 5825, 1990. 